\title{
Desemprego e inatividade nas metrópoles brasileiras: as diferenças entre homens e mulheres
}

\author{
Pedro Rodrigues de Oliveira \\ Mestre pela FEA-RP/USP \\ e Doutorando pela ESALq/USP \\ Luiz Guilherme Scorzafave \\ FEA-RP/USP \\ Elaine Toldo Pazello \\ FEA-RP/USP e INEP-MEC
}

\section{Palauras-chave \\ desemprego, inatividade, mulher, mercado de trabalho, participação.}
Classificação JEL J16, J21, $\mathrm{J} 64$.

Key words

unemployment, inactivity, woman, labor market, participation.

JEL Classification J16, J21, J64.

\section{Resumo}

Analisar a evolução recente da estrutura do desemprego e da inatividade nas metrópoles brasileiras é o objetivo deste trabalho. Além de um panorama geral, foram realizadas análises separadas por gênero. A resposta da inatividade para a variável "número de crianças no domicílio" é a que mais se destaca: há uma relação negativa para os homens, e positiva para as mulheres. Além disso, os padrões observados entre mulheres pobres e não pobres são muito diferenciados - a inatividade para as mulheres de renda baixa é significativamente maior -, refletindo diferenças de escolaridade e, provavelmente, dificuldades de acesso à creche.

\section{Abstract}

This paper examines the recent evolution of unemployment and inactivity in Brazilian metropolitan areas. We analyze the situation of men and women separately. The variable "number of children in household" is the most prominent factor concerning inactivity: it is inversely related to male inactivity and directly related to female inactivity. Moreover, the observed patterns among poor and non-poor women are extremely different - poor women have higher inactivity rates than non-poor women - reflecting schooling differentials and, probably, difficulty in enrolling their children in adequate daycare facilities. 


\section{1_Introdução}

A questão do desemprego subiu ao topo da agenda econômica no Brasil desde a década de noventa, quando se observou aumento na sua incidência. O crescimento do desemprego, embora generalizado, atingiu mais fortemente as mulheres e os indivíduos com escolaridade intermediária, além de ser mais pronunciado entre os jovens. Esses fatos provocaram um incremento nas pesquisas acadêmicas sobre a temática do desemprego (MenezesFilho e Picchetti, 2000; Camargo e Reis, 2005; Reis, 2006; entre outros).

Mas a questão do desemprego sempre esteve na agenda de pesquisas. Barros et al. (1997) analisaram a estrutura do desemprego - incidência e duração - com base na Pesquisa Mensal de Emprego (PME), entre os anos de 1982 e 1993. Os autores estavam interessados em saber como o desemprego se distribuía entre os diversos grupos sociais, visto que a preocupação era com o impacto do desemprego sobre a pobreza e a desigualdade de renda. $\mathrm{O}$ argumento utilizado pelos autores era que, a depender da estrutura do desemprego, o impacto desse sobre pobreza e desigualdade poderia ser grande, mesmo sendo sua incidência baixa. Os resultados encontrados pelos autores mostraram que tal impacto do desemprego sobre pobreza e distribuição da renda familiar era, de fato, limitado tendo em vista que esse se concentrava em alguns segmentos (jovens, filhos, cônjuges e mulheres), cuja contribuição para o orçamento familiar era pequena.

Em outro artigo, também com dados mais antigos, Fernandes e Picchetti (1999), utilizando a Pesquisa Nacional por Amostras de Domicílios de 1995, analisaram os efeitos de diferentes características socioeconômicas sobre as probabilidades não só do desemprego, como em Barros et al. (1997), mas também sobre a inatividade dos indivíduos. A ideia básica é que indivíduos com diferentes características possuem distintas probabilidades de engajamento no mercado e de desemprego. Tais peculiaridades devem ser levadas em consideração ao se analisar o comportamento da estrutura do desemprego ${ }^{2}$ e da inatividade. Esses autores estimaram um logit multinomial para modelar as "decisões" de inatividade, desocupação e ocupação. Os resultados encontrados mostravam que, de modo geral, as variáveis que aumentavam a probabilidade de um indivíduo se encontrar desempregado também o faziam em relação à inatividade.

A duração do desemprego, o outro aspecto analisado em Barros et al. (1997), também já foi analisada por outros autores, valendo-se dos dados da PME. Bivar (1991) $\ldots \ldots$ Há outros estudos interessados na relação entre desemprego e pobreza e desigualdade de renda. Barros, Corseuil e Leite (1999), por exemplo, encontram que a eliminação do desemprego resultaria em uma queda de $7,4 \%$ na fração de pobres em 1995; Fernandes, Pazello e Felicio (2002), uma redução na fração de pobres em 31,8\% para 1999, ano em que a taxa de desemprego era relativamente maior que a de 1995 (6,7\% em 1995 e 10\% em 1999). Ferreira e Barros (1999) também encontram que aumentos do desemprego elevam a pobreza e a desigualdade de renda.

2 Flori (2003), por exemplo, analisou a questão do desemprego entre jovens brasileiros. Segundo a autora, o principal determinante da alta taxa de desemprego para os jovens não residia na dificuldade em conseguir (o primeiro) emprego, e sim na elevada taxa de rotatividade (troca constante de emprego) que caracterizava esse grupo. 
é responsável pelo artigo pioneiro no Brasil sobre o tema. A autora calculou a duração média do desemprego para os dados brasileiros, mas sem incorporar características socioeconômicas na análise. Menezes-Filho e Picchetti (2000), utilizando outras ferramentas de análise, complementaram Bivar (1991). Seus resultados mostraram que a duração esperada do desemprego era menor para os chefes de familia e para os que já tinham trabalhado anteriormente; por outro lado, era maior para os de nível educacional mais elevado, para os mais idosos e para aqueles que, no emprego anterior, haviam sido demitidos. Vale destacar que Menezes-Filho e Picchetti (2000) focam a Região Metropolitana de São Paulo. Outros estudos foram feitos sobre duração de desemprego analisando outras regiões metropolitanas, como, por exemplo, Menezes-Filho e Picchetti (2002).

Além dos trabalhos mais genéricos a respeito da incidência e duração do desemprego, há estudos que buscam analisar o impacto das políticas públicas e do próprio ambiente econômico sobre o desemprego. Por exemplo, o efeito da estabilização dos preços sobre o desemprego foi o tema do trabalho de Reis e Camargo (2007). Segundo os autores, haveria uma assimetria de informação na relação de trabalho entre o trabalhador e a empresa; e, apenas com o pas- sar do tempo de emprego, é que a empresa descobriria a verdadeira produtividade do trabalhador. Nesse contexto, a inflação elevada permitia às empresas realizar um ajuste nos salários reais, mesmo na presença de salários nominais rígidos, caso a produtividade do trabalhador se mostrasse diferente da esperada. No entanto, com a queda da inflação, na medida em que um trabalhador se revelasse pouco produtivo, a tendência seria de a empresa demiti-lo, dada a maior dificuldade para ajuste no salário real. Assim, as hipóteses testadas são de que a queda da inflação aumentaria o desemprego e diminuiria a duração do emprego. Os autores encontraram evidências robustas que ratificam essa hipótese, e o efeito é mais pronunciado para trabalhadores jovens de 18 a 20 anos e semiqualificados (4-10 anos de estudo), para os quais a assimetria de informação quanto à verdadeira produtividade seria maior.

O presente artigo está em linha com o trabalho de Fernandes e Picchetti (1999), ou seja, busca analisar o impacto de diversas características socioeconômicas sobre as probabilidades de desemprego e inatividade. No entanto, diferentemente desses autores, aqui a estimação é feita separadamente para homens e mulheres. Podemos destacar alguns argumentos que motivaram esta análise. Primeiramente, a dinâmica 
do desemprego e da inatividade, bem como a resposta das características socioeconômicas a esses eventos, pode ser bem diferente para homens e mulheres. Por exemplo, espera-se que a presença de filhos pequenos não afete a inatividade masculina, mas afete consideravelmente a feminina. Um segundo ponto está relacionado às diferentes trajetórias em termos de engajamento no mercado de trabalho que vêm sendo observadas para homens e mulheres. Como colocado inicialmente, o aumento recente do desemprego tem sido mais forte para as mulheres.

Paralelamente a isso, nas últimas décadas, verificou-se um aumento do engajamento das mulheres no mercado de trabalho e certa estagnação entre os homens (Scorzafave e Menezes-Filho, 2001). Assim, é possível que haja alguma correlação entre os movimentos da inatividade e do desemprego, especialmente para as mulheres, na medida em que o maior ingresso dessas no mercado de trabalho possa não estar encontrando respaldo em termos de postos de trabalho disponíveis. Por fim, enquanto Fernandes e Picchetti (1999) usaram dados de 1995, o presente artigo trabalha com dados mais atuais (de 2004). Desse modo, a atualização dos resultados do artigo anterior também é uma motivação para o estudo. De fato, Hamermesh (2007, p. 715) aponta que "os economistas tratam a questão da replicação da mesma forma que os adolescentes tratam a castidade - como um ideal a ser propagado, mas não para ser praticado". Para ressaltar a importância desse tipo de estudo, Hamermesh (2007) argumenta que

one cannot expect econometric results produced for one time period or for one economy to carry over to another. Temporal change in econometric structure may alter the size and even the sign of the effects being estimated, so that the bypotheses we are testing might fail to be refuted with data from another time. This alteration might occur because institutions change, because incentives that are not accounted for in the model change and are not separable from the behaviour on which the model focuses, or, crucially, that even without these changes the behaviour is dependent on random shocks specific to the period over which an economy is observed (Hamermesh, 2007, p. 727).

Desta forma, o presente trabalho tem o intuito de estudar a estrutura do desemprego e de inatividade nas regiões metropolitanas brasileiras, utilizando a Pesquisa Nacional por Amostra de Domicílios (PNAD) para o ano de 2004. A análise realizada em Fernandes e Picchetti (1999) será atualizada de forma a identificar quais fatores passaram a atuar mais (ou menos) for- 
temente como determinantes do desemprego e da inatividade e que, desse modo, devam ser alvo de políticas públicas. No entanto, diferentemente de Fernandes e Picchetti (1999), neste artigo as estimações são desagregadas para homens e mulheres. Assim, analisa-se qual o impacto de características como idade, anos de estudo, posição no domicílio, número de crianças no domicílio, etc., sobre a probabilidade de desemprego e de inatividade separadamente para homens e mulheres.

$\mathrm{O}$ artigo está dividido em três seções, além desta introdução. A seção seguinte apresenta os dados e a metodologia empregados no trabalho. A seção 3 fornece os resultados da análise descritiva e econométrica, bem como os resultados das simulações. Por fim, a seção 4 traz as conclusões.

\section{2_Dados e metodologia}

\section{1_Dados}

3 A renda domiciliar líquida é definida como a renda domiciliar de todas as fontes, excluída a renda de todas as fontes do próprio indivíduo. Caso apenas um indivíduo tenha renda positiva, a renda domiciliar líquida dele será zero. de interesse do trabalho, o que resultou em uma amostra de 107.376 indivíduos. Cabe destacar aqui que essas mesmas restrições na amostra foram adotadas em Fernandes e Picchetti (1999), de modo que é possível, assim, comparar nossos resultados com o desse estudo.

Foram incluídas as mesmas variáveis explicativas que aparecem no trabalho de Fernandes e Picchetti (1999), a saber: anos de estudo, idade, renda domiciliar líquida, ${ }^{3}$ sexo, raça, condição na família e condição referente à aposentadoria. O Quadro 1 descreve tais variáveis. A variável dependente, por sua vez, admite três categorias: ocupado, inativo e desempregado.

A justificativa para o uso das variáveis de educação e de idade com seus respectivos termos quadráticos decorre do fato de haver evidências empíricas de uma relação não linear de ambas com o desemprego e a inatividade (Mello et al., 2006). Por sua vez, espera-se que quanto maior a renda domiciliar líquida, menor seja o incentivo para o indivíduo ingressar no mercado de trabalho. Já um maior número de crianças no domicílio deve diminuir a probabilidade de desemprego e de inatividade de homens, uma vez que o custo de oportunidade de não trabalhar seria mais elevado por haver mais crianças para ser sustentadas no domicílio. 
Quadro 1_Variáveis explicativas utilizadas

\begin{tabular}{|c|c|}
\hline anoest & Anos de estudos dos indivíduos, variando de 0 a 18. \\
\hline anoest2 & Número de anos de estudo elevados ao quadrado. \\
\hline idade & Idade dos indivíduos. \\
\hline idade2 & Idade elevada ao quadrado. \\
\hline renda_liq & Renda domiciliar de todas as fontes excluindo-se a renda do indivíduo. \\
\hline bomem & Variável dummy que é igual a 1 se o indivíduo é do sexo masculino. \\
\hline ncrianças & Número de crianças (menores de 10 anos de idade) no domicílio. \\
\hline nadultos & Número de adultos (10 ou mais anos de idade) no domicílio. \\
\hline pardo & Dummy que é igual a 1 se o indivíduo é pardo. \\
\hline negro & Dummy que é igual a 1 se o indivíduo é negro. \\
\hline filho & Dummy que é igual a 1 se o indivíduo é filho. \\
\hline cônjuge & Dummy que é igual a 1 se o indivíduo é cônjuge. \\
\hline outra_cond & Dummy que é igual a 1 se o indivíduo não é chefe, filho ou cônjuge. \\
\hline aposent & Dummy que é igual a 1 se o indivíduo recebe algum tipo de aposen \\
\hline
\end{tabular}

Fonte: Elaboração própria.

Para as mulheres, o efeito esperado é dúbio, já que, se, de um lado, a mesma racionalidade aplicada aos homens é válida, de outro, mais crianças exigem maior dedicação de tempo ao cuidado delas, o que desincentivaria o ingresso das mulheres no mercado de trabalho. Lógica semelhante é válida para o número de adultos: quanto maior esse número, menor é o custo de oportunidade de um particular indivíduo do domicílio ingressar no mercado de trabalho ou de permanecer desempregado.
As variáveis binárias pardo e negro captam diferenças na incidência de inatividade e de desemprego para pessoas de diferentes raças. Espera-se maior incidência de desemprego entre pardos e negros, fruto de potencial processo discriminatório e/ou do efeito de características não observáveis (como a qualidade da educação, por exemplo) sobre a probabilidade de desemprego. As variáveis binárias que captam a posição da pessoa no domicílio também refletem a consideração de que o custo de 
oportunidade de inatividade/desemprego é maior para o chefe do domicílio do que para os demais membros.

Por fim, a variável aposent busca verificar se o fato de um indivíduo receber aposentadoria aumenta a probabilidade de inatividade e diminui a de desemprego. Para o caso brasileiro, faz sentido considerar essa variável no modelo, já que Mello et al. (2006) apontam que, em 2004, 28\% dos aposentados com 64 anos de idade continuavam trabalhando.

\subsection{Metodologia}

Para obter as probabilidades associadas aos estados de inatividade e desemprego, estimaram-se modelos logit multinomial (a categoria-base é a de "ocupados").

$$
p_{i j}=\Lambda\left(x_{i}, \beta\right)=\frac{\exp \left\{x_{i}^{\prime} \beta_{j}\right\}}{\sum_{l=1}^{m} \exp \left\{x_{i}^{\prime} \beta_{j}\right\}}
$$

$j=1, \ldots, m ; i=1, \ldots, n$.

onde o subscrito $i$ denota o indivíduo, e o subscrito $j$ ou $l$ denotam os estados; $x_{i}$ representa um vetor com os valores das $k$ covariadas para o indivíduo $i ; \Lambda$ representa a função de distribuição cumulativa logística e $p_{i j}$ denota a probabilidade do indivíduo $i$ estar no estado $j$. No nosso estudo, $m=3$ (ocupado, desocupado, inativo).
Com a estimação dos parâmetros $\beta$ do logit multinomial por máxima verossimilhança, foram realizadas simulações de impacto sobre a probabilidade de desemprego e inatividade para as seguintes variáveis: anos de estudo, idade, renda domiciliar líquida, número de filhos, número de adultos e cor da pele. Essas simulações permitem melhor visualização dos efeitos marginais dessas variáveis nas probabilidades de interesse, facilitando a análise comparativa dos resultados para homens e mulheres. Mais formalmente, podem-se escrever as probabilidades previstas de cada estado $j$ para cada indivíduo $i$, como:

$$
\hat{p}_{i j}=\Lambda\left(x_{i}, \hat{\beta}\right)=\frac{\exp \left\{x_{i}{ }_{i}^{\prime} \hat{\beta}_{j}\right\}}{\sum_{l=1}^{m} \exp \left\{x_{i}{ }_{i} \hat{\beta}_{j}\right\}}
$$

Para cada variável explicativa, o procedimento de simulação consiste em recalcular as probabilidades estimadas para todos os indivíduos, substituindo-se diferentes valores da variável explicativa a ser examinada. Suponha que uma variável explicativa $x^{0}$ qualquer assuma $t$ diferentes valores na amostra:

$x_{\min }^{0}=x_{1}^{0}<x_{2}^{0}<x_{3}^{0}<\ldots<x_{t}^{0}=x_{\max }^{0}$

Então, para todos os indivíduos da amostra, substitui-se o valor observado de 
$x^{0}$ por $x_{\min }^{0}$ e recalculam-se as probabilidades para cada indivíduo. Assim, ignorando o subscrito $i$ :

$\hat{p}_{j}^{x_{\min }^{0}}=\Lambda\left(x^{0}, x^{-0}, \hat{\boldsymbol{\beta}}\right)=\frac{\exp \left\{x^{-0} \hat{\boldsymbol{\beta}}_{j}^{-0}+x_{\min }^{0} \hat{\boldsymbol{\beta}}_{j}^{0}\right\}}{\sum_{l=1}^{m} \exp \left\{x^{\prime} \hat{\boldsymbol{\beta}}_{l}\right\}}$

onde $x^{-0}$ representa as demais variáveis explicativas exceto $x^{0} ; \hat{\beta}_{j}^{-0}$ representa o vetor estimado de coeficientes referente aos regressores $x^{-0} ; \hat{\beta}_{j}^{0}$ representa o coeficiente estimado da variável $x^{0}$ do estado $j$.

A média de $\hat{p}_{j}^{x_{\min }^{0}}$ para todos os indivíduos corresponde à probabilidade esperada do estado $j$ se $x^{0}=x_{\min }^{0}$ :

$\overline{\hat{p}}_{j}^{x_{\min }^{0}}=\frac{\sum_{i=1}^{n} \hat{p}_{j}^{x_{\min }^{0}}}{n}$

Repetindo o mesmo procedimento para os demais $t-1$ valores que $x^{0}$ pode assumir, encontra-se $\overline{\hat{p}}_{j}^{x_{2}^{0}}, \overline{\hat{p}}_{j}^{x_{3}^{0}}, \ldots, \overline{\hat{p}}_{j}^{x_{\max }^{0}}$.

Através desse procedimento, é possível, então, construir um gráfico associando os diferentes valores que $x^{0}$ pode assumir com as respectivas probabilidades $\overline{\hat{p}}_{j}^{x_{t}^{0}}$.

Vale salientar aqui que, com relação às simulações, se deve levar em conta que essa oferece informações mais precisas em termos relativos do que absolutos. Isso acontece porque, ao atribuir o mesmo valor de uma determinada variável para toda a amostra, se criam observações simuladas que são impossíveis de existir na população, como, por exemplo, um indivíduo que tenha 10 anos de idade e 12 anos de estudo. Nesse exemplo, provavelmente tal procedimento estaria aumentando a probabilidade média de um garoto de 10 anos de estar empregado, em função da relação positiva entre escolaridade e ocupação. É difícil precisar os efeitos positivos e negativos sobre as probabilidades; assim, é importante olhar com cuidado esses valores. Além disso, na medida em que se caminha para os extremos da distribuição, perde-se precisão nas estimativas. A análise relativa, porém, traz informações valiosas, permitindo olhar dentro do intervalo da variável quais valores têm maior ou menor efeito sobre as probabilidades simuladas.

Como já foi colocado, o presente artigo analisa o comportamento de homens e mulheres separadamente em relação ao desemprego e à inatividade. Vários fatores levam a diferentes comportamentos de homens e mulheres com relação ao mercado de trabalho, o que influenciaria as probabilidades de desemprego e inatividade diferentemente para os dois sexos. Para testar essa hipótese, dividiu-se a amostra 
4 De modo geral, as estimativas de desemprego com os dados da PNAD ficaram 2 p.p. acima das relativas à Pesquisa de Emprego e Desemprego (PED), elaborada pela Fundação Sistema Estadual de Análise de Dados (SEADE), e 3 p.p. acima daqueles oriundos da Pesquisa Mensal de Emprego (PME), elaborada pelo Instituto Brasileiro de Geografia e Estatística (IBGE). em duas (homens e mulheres) e estimou-se o modelo para cada subamostra, visando verificar se os coeficientes das regressões diferem entre si e em relação aos da amostra completa.

\section{3_Resultados}

\section{1_Análise descritiva}

Antes da análise dos resultados do modelo econométrico, apresentam-se algumas estatísticas descritivas. O Gráfico 1 mostra as taxas de inatividade e desemprego, segundo o gênero e anos de estudo.

Com relação à taxa de inatividade, há uma relação inversa com a escolaridade, refletindo o maior custo de oportunidade da inatividade quanto maior a educação do indivíduo. As mulheres apresentaram taxas de inatividade bem superiores a dos homens, e se compararmos com os resultados de Fernandes e Picchetti (1999) para 1995 , as taxas praticamente não se alteraram entre os homens e diminuíram (de $53 \%$ para $48 \%$ ) entre as mulheres.

Com relação ao desemprego em 2004, tem-se uma taxa geral da ordem de 13,4\%, sendo $10,9 \%$ entre os homens e $16,5 \%$ entre as mulheres nas regiões metropolitanas. Tanto para os homens quanto para as mulheres, as maiores taxas de desemprego são observadas para aqueles que têm de 5 a 11 anos de estudo.
Comparando com os dados da PNAD de 1995 apresentados em Fernandes e Picchetti (1999), houve elevação do desemprego em todos os grupos no período. A taxa de desemprego em 1995 era de $7,8 \%$ para os homens e de $10,8 \%$ entre as mulheres, o que totalizou uma taxa geral de $9,1 \%$. Houve, portanto, um aumento na taxa de desemprego de $38 \%$ para os homens e de $54 \%$ para as mulheres. O grupo que apresentava maior taxa de desemprego em 1995 era o dos que possuíam de 5 a 8 anos de estudo, ${ }^{4}$ em 2004; o maior índice de desemprego está entre os que têm entre 9 e 11 anos de estudo (16,3\%) seguido de perto pelos com 5 a 8 anos de estudo (16\%).

A seguir, no Gráfico 2, são apresentados os resultados de acordo com faixas etárias. A taxa de inatividade na população atinge seu valor mínimo entre as idades de 31 e 45 anos. Os dados correspondem ao que se espera de um ciclo natural de entrada e saída do mercado de trabalho ao longo do ciclo de vida. Mas é interessante notar que, apenas para a faixa etária mais nova, a taxa de inatividade é semelhante para homens e mulheres. Para as demais faixas, a participação masculina e feminina no mercado de trabalho apresenta taxas bastante diferentes, sendo a taxa de inatividade entre as mulheres mais que o dobro da taxa masculina. 
Gráfico 1_ Taxas de inatividade e desemprego segundo gênero e anos de estudo

\section{Homens}

\section{Inatividade}

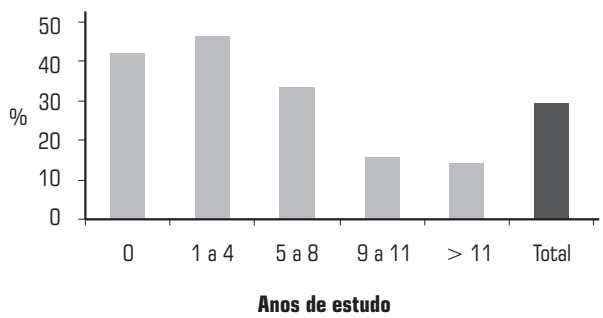

\section{Mulheres}

\section{Inatividade}

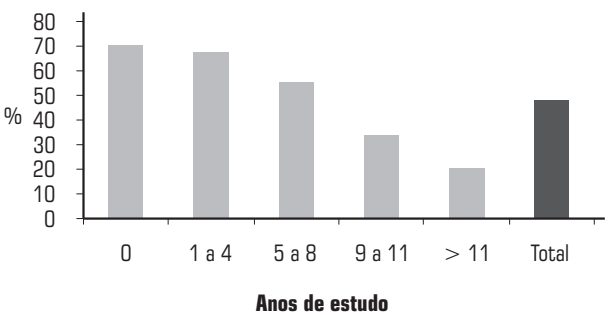

Total

\section{Inatividade}

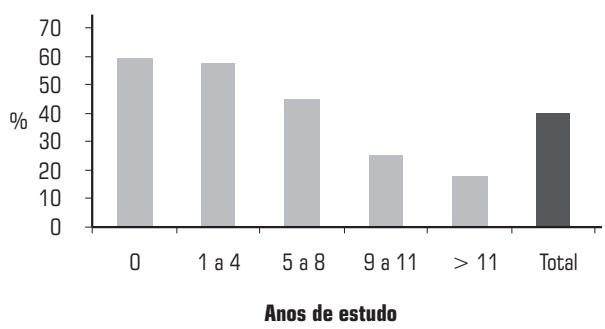

\section{Desemprego}

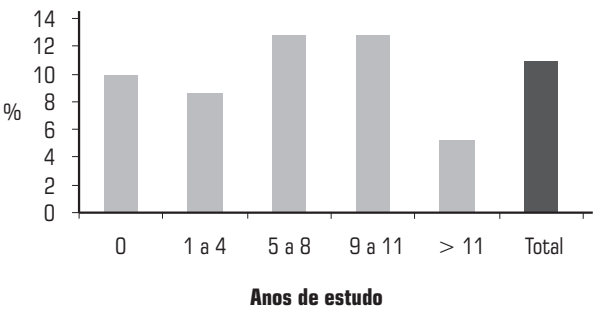

\section{Desemprego}

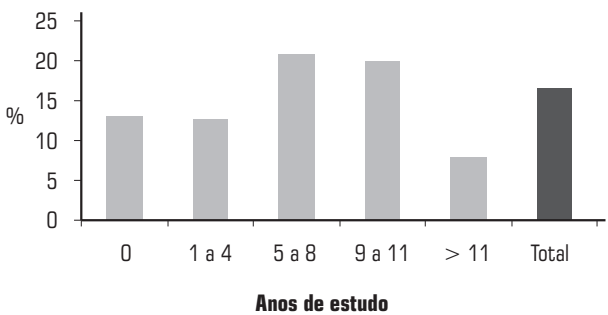

\section{Desemprego}

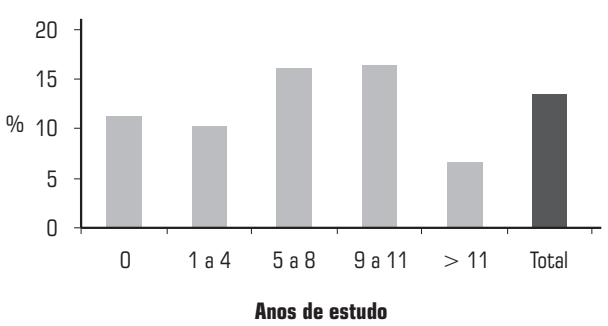

Fonte: Elaboração própria, com base nos dados da PNAD de 2004. 
Gráfico 2_ Taxas de inatividade e desemprego segundo gênero e anos de estudo

\section{Homens}

\section{Inatividade}

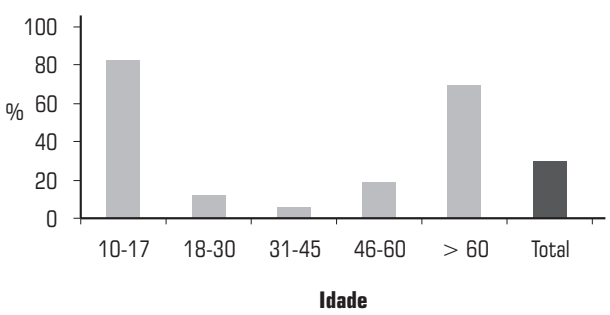

\section{Mulheres}

Inatividade

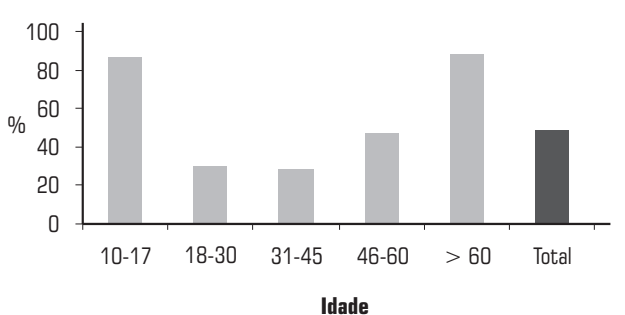

\section{Total}

Inatividade

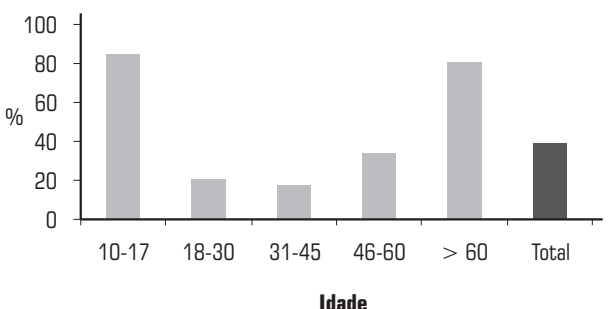

\section{Desemprego}

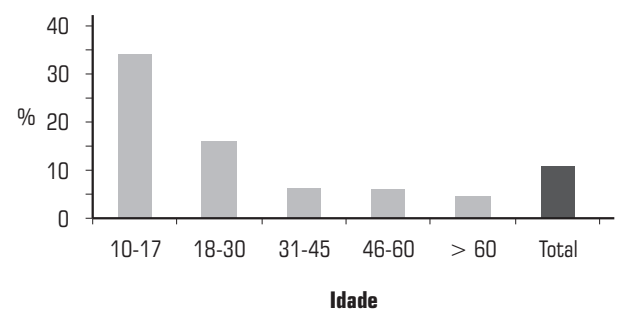

\section{Desemprego}

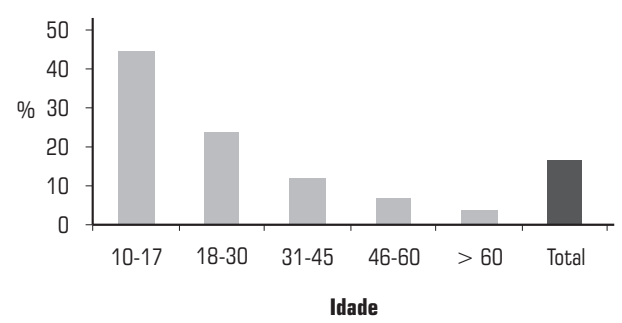

\section{Desemprego}

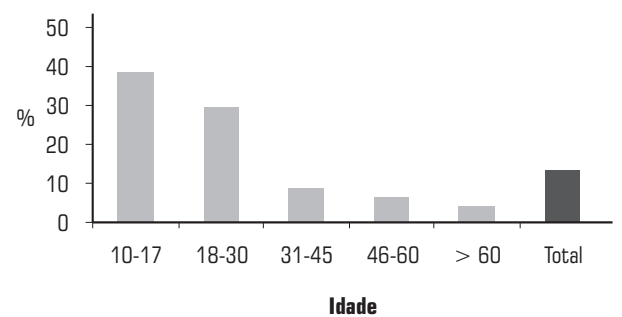

Fonte: Elaboração própria, com base nos dados da PNAD de 2004. 
Com relação ao desemprego, os dados do Gráfico 2 indicam uma relação inversa entre taxa de desemprego e idade: enquanto entre os mais jovens a taxa de desemprego é de $38,5 \%$, entre os mais velhos é de 4,4\%. O maior desemprego entre os jovens pode refletir, como aponta Flori (2003), a maior rotatividade desse grupo, que, por sua vez, pode decorrer da maior assimetria de informação na relação de trabalho no caso de trabalhadores jovens (Camargo e Reis, 2005). Assim, a maior incerteza quanto à verdadeira produtividade de um trabalhador jovem no momento da contratação levaria a maior taxa de demissão de jovens à medida que a assimetria informacional fosse sendo eliminada. Assim, esse processo levaria a maior taxa de desemprego e de rotatividade entre eles.

Outro fator que pode estar por detrás do maior desemprego entre os jovens é o fato de o custo de oportunidade do desemprego ser menor nesse grupo, dado que, na maioria das famílias, o jovem não é o principal provedor da renda domiciliar, podendo, então, ser mais seletivo na escolha de uma ocupação. Por sua vez, a taxa de desemprego é maior entre as mulheres, para todos os grupos etários, exceto entre as com mais de 60 anos, algo razoável, já que a inatividade feminina nessa faixa etária é elevada, significando que há poucas mulheres que "esco-lhem" ficar desocupadas.
A distribuição de desemprego por faixa etária possui o mesmo padrão do encontrado por Fernandes e Picchetti (1999), com o decréscimo do desemprego conforme aumenta a idade. Como esperado, para todas as faixas etárias, a da taxa de desemprego atual é maior, em torno de $35 \%$ a $40 \%$, destacando-se no geral o aumento do desemprego entre os mais jovens. Contudo, a análise das diferenças por gênero mostra padrões diferentes de alteração do desemprego. Entre os homens, o maior aumento se deu entre aqueles com até 30 anos, enquanto entre as mulheres o maior aumento se deu na faixa dos 46 aos 60 anos. Esse dado sobre as mulheres chama bastante a atenção, já que o senso comum levaria a pensar num aumento maior de desemprego entre as mais jovens.

Por fim, são descritas as taxas de inatividade e de desemprego de acordo com a posição na família. Os chefes de família apresentam menores taxas de inatividade $\mathrm{e}$ de desemprego, ao passo que os filhos apresentam as maiores. Isso se deve ao fato de que o custo de oportunidade de estar desempregado ou inativo é maior para o chefe do domićlí, dado que ele é o maior provedor dos recursos domiciliares. Note que isso é verdade também para o caso das mulheres chefes, que possuem menor desemprego e inatividade que as demais (Gráfico 3). 


\section{Gráfico 3_ Taxas de inatividade e desemprego segundo gênero e anos de estudo}

\section{Homens}

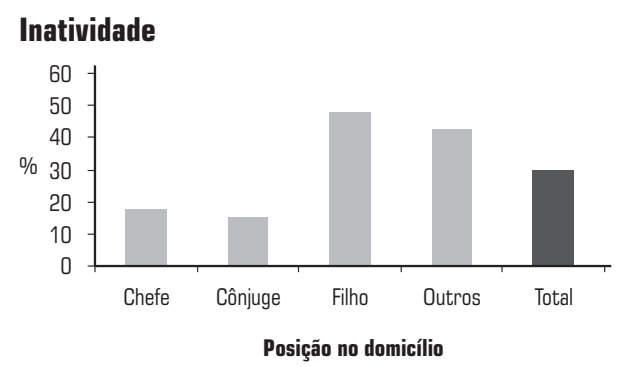

Desemprego

\section{Mulheres}

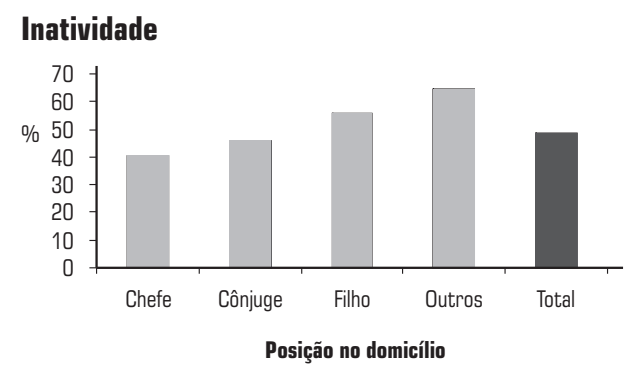

\section{Desemprego}

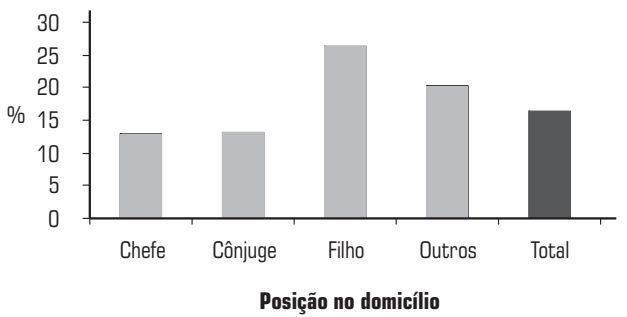

\section{Total}

\section{Inatividade}

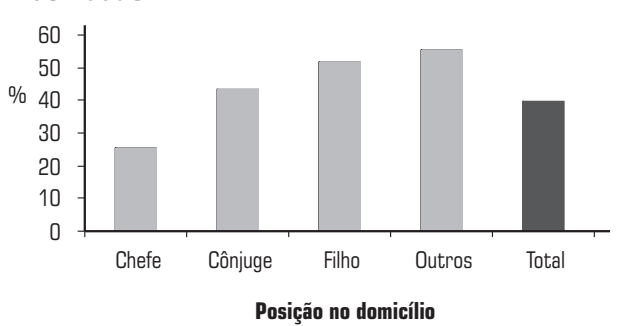

\section{Desemprego}

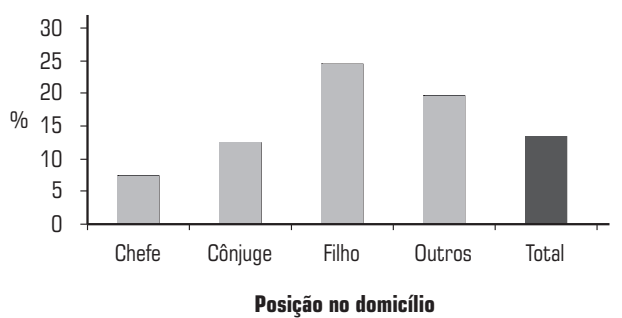

Fonte: Elaboração própria, com base nos dados da PNAD 2004. 


\section{2_ Resultados da estimação}

Uma das principais diferenças deste trabalho com relação ao de Fernandes e Picchetti (1999) é que o logit multinomial é estimado separadamente para homens e mulheres. Para saber se essa estratégia de separação da amostra é válida, realizouse o teste de razão de verossimilhança para a hipótese nula de que os coeficientes para homens e mulheres são iguais a um nível de significância de 1\%. O resultado do teste permitiu rejeitar a hipótese de igualdade dos coeficientes, o que possibilita analisar a amostra separadamente para homens e mulheres. ${ }^{5}$

Os logits multinomiais estimados com os dados de 2004 apresentaram um padrão diferente do de Fernandes e Picchetti (1999), conforme pode ser visualizado na Tabela 1.

Com relação à variável dependente "inatividade", os sinais de educação para homens e mulheres são diferentes entre si e com relação aos da PNAD de 1995. Entretanto, para as variáveis de idade, renda domiciliar líquida, filho, outra condição e aposentado, os sinais são os mesmos. Destaca-se o resultado das dummies de raça, que mostraram maior probabilidade de inatividade para mulheres negras e pardas e nenhuma diferença por raça nessa probabilidade entre os homens.
Já para a variável dependente "desemprego", as variáveis de número de crianças e número de adultos são não significativas para homens, e positivas e significativas para mulheres. Além disso, há diferença no sinal dos coeficientes das dummies para metrópoles, com algumas se tornando significativas em 2004, principalmente para as mulheres. Por outro lado, o sinal e a significância das variáveis de educação se mantiveram e foram os mesmos para homens e mulheres. Os sinais indicam um formato de $U$ invertido na relação entre escolaridade e desemprego. Ou seja, os indivíduos com baixa e os com alta escolaridade têm menor probabilidade de desemprego do que aqueles com escolaridade intermediária.

Em Fernandes e Picchetti (1999) já era possível perceber a diferença de resultados da variável "número de crianças no domicílio" para homens e mulheres, a partir da inclusão no modelo de uma interação dessa variável com a dummy homem. Esses autores encontraram que, para as mulheres, quanto maior o número de crianças no domicílio, maior a inatividade e o desemprego; para os homens, o impacto da variável "número de crianças" é negativo para as duas probabilidades, mas pouco importante. Esses resultados também foram obtidos no presente artigo. coeficientes os efeitos marginais dos logits multinomiais, para homens e mulheres, estão no Apêndice. 
Tabela 1_Sinal dos coeficientes das regressões

\begin{tabular}{|c|c|c|c|c|c|c|}
\hline \multirow{3}{*}{ Variável } & \multirow{2}{*}{\multicolumn{2}{|c|}{1995}} & \multicolumn{4}{|c|}{2004} \\
\hline & & & \multicolumn{2}{|c|}{ Homem } & \multicolumn{2}{|c|}{ Mulher } \\
\hline & Desemprego & Inatividade & Desemprego & Inatividade & Desemprego & Inatividade \\
\hline Escolaridade & + & - & + & - & + & + \\
\hline Escolaridade $^{2}$ & - & - & - & NS & - & - \\
\hline Idade & - & - & - & - & NS & - \\
\hline Idade $^{2}$ & - & + & NS & + & - & + \\
\hline Renda Líquida & - & + & - & + & - & + \\
\hline Homem & - & - & & & & \\
\hline No.Crianças & + & + & NS & - & + & + \\
\hline Homem*Criança & - & - & & & & \\
\hline No Adultos & NS & - & NS & NS & + & NS \\
\hline$\underline{\text { Homem*Adulto }}$ & + & + & & & & \\
\hline Pardo & NS & - & NS & NS & NS & - \\
\hline Negro & NS & - & + & NS & NS & - \\
\hline Filho & + & + & + & + & + & + \\
\hline Cônjuge & + & + & + & - & NS & + \\
\hline Outra Condição & + & + & + & + & NS & + \\
\hline Aposentado & + & + & + & + & NS & + \\
\hline Belém & NS & + & - & NS & - & + \\
\hline$\underline{\text { Fortaleza }}$ & NS & - & - & NS & - & + \\
\hline Recife & NS & + & NS & + & + & + \\
\hline Salvador & NS & + & NS & NS & + & NS \\
\hline Belo Horizonte & - & - & - & - & - & - \\
\hline Rio de Janeiro & NS & + & - & + & NS & + \\
\hline Curitiba & - & - & - & - & - & - \\
\hline Porto Alegre & - & - & - & - & - & - \\
\hline Constante . . & & & $\therefore$. & + & - &.+ \\
\hline
\end{tabular}

Legenda: NS = não significativo a $1 \%$

Fonte: PNAD 1995, de Fernandes e Picchetti (1999). PNAD 2004, elaboração própria. 
Para os homens, a variável "número de crianças" apresenta efeito negativo para a probabilidade de inatividade e não significante para a probabilidade de desemprego. Para as mulheres, a variável apresenta resultado positivo para as duas probabilidades. Entretanto, no caso do desemprego, a variável "número de crianças" também não foi estatisticamente significativa a 10\% quando se analisa o efeito marginal dessa variável considerando-se uma mulher de características médias.

Enfim, os multinomiais demonstraram que a análise conjunta de homens e mulheres negligencia informações importantes a respeito de como as variáveis explicativas afetam diferentemente a inatividade e o desemprego de homens e mulheres.

\section{3_Simulações}

A partir de agora, são analisados os resultados da simulação explicitada na seção 2. Assim, com base nas estimativas dos parâmetros, foram feitas simulações de impacto sobre a probabilidade de inatividade e desemprego para homens e mulheres para as seguintes variáveis: anos de estudo, idade, renda domiciliar líquida, número de crianças no domicílio, número de adultos e raça. Como já dissemos, as simulações permitem melhor visualização dos efeitos marginais dessas variá- veis nas probabilidades de interesse $\mathrm{e}$ maior facilidade em se distinguir os resultados para homens e mulheres.

\subsection{1_Anos de estudo}

Com relação à inatividade, nota-se, por meio da análise do Gráfico 4, que ela é decrescente em relação aos anos de estudo e que as mulheres sempre apresentam probabilidade de inatividade maior que os homens, tudo o mais constante. Aparentemente a maior parte da explicação dessa diferença se deve a bem conhecidos fatores culturais relacionados com a divisão familiar do tempo, que leva parte das mulheres a se especializar em atividades domésticas.

Outra verificação é que a diferença na probabilidade de inatividade entre os sexos diminui com a escolaridade, refletindo o maior custo de oportunidade para mulheres mais educadas de não ingressar no mercado de trabalho. Mais uma vez, as simulações corroboram a análise descritiva de relação inversa entre inatividade e educação.

A relação entre desemprego e anos de estudo tem formato de $\mathrm{U}$ invertido, padrão semelhante ao encontrado em Fernandes e Picchetti (1999), com a maior probabilidade de desemprego ocorrendo para indivíduos com 10 anos de estudo. Entretanto, esse resultado é diferente para homens e mulheres. 


\section{Gráfico 4_Impacto da escolaridade sobre a inatividade}

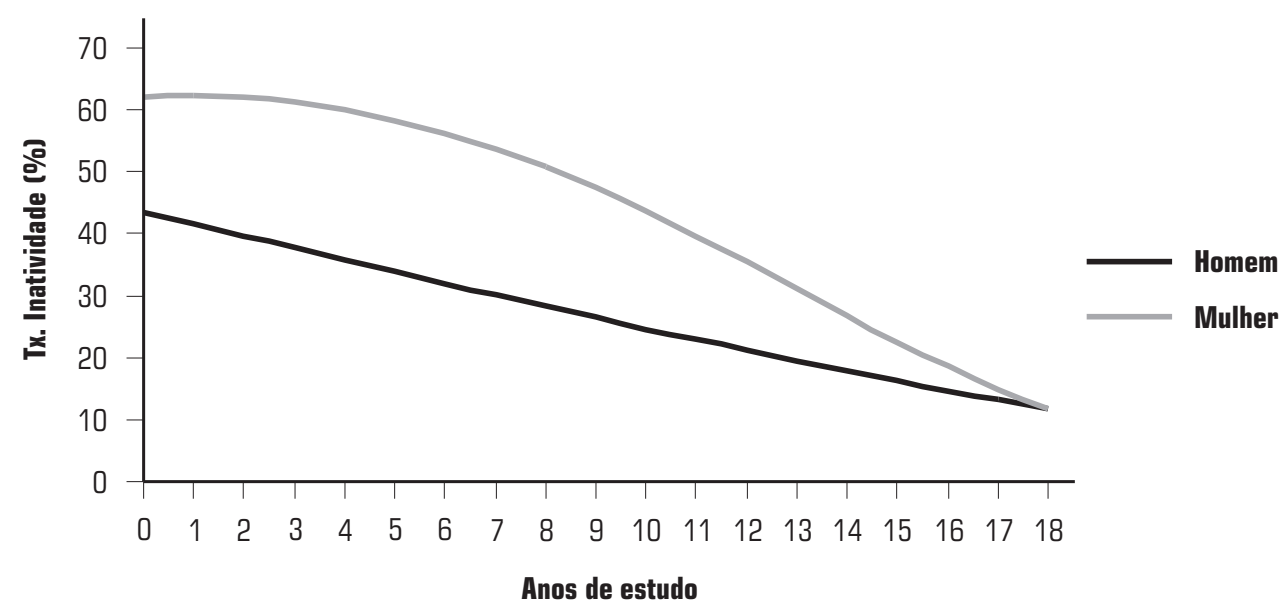

Fonte: Elaboração própria com base nos dados da PNAD 2004 e nas simulações.

Para os homens, a probabilidade simulada máxima ocorre com nove anos de estudo, enquanto para as mulheres ocorre aos 11 anos de estudo. Além disso, não há praticamente diferença na probabilidade de desemprego entre os gêneros até cinco anos de estudo. A partir de então, a probabilidade de desemprego da mulher passa a ser maior que a do homem. As simulações corroboram as estatísticas descritivas, com as maiores taxas de desemprego ocorrendo entre aqueles que têm entre ensino fundamental e ensino médio, porém, marcando mais acentuadamente a alta taxa de desem- prego entre aqueles com ensino médio (Gráfico 5).

\subsection{2_ Idade}

Os resultados no Gráfico 6 da simulação de probabilidade de inatividade com relação à idade também estão de acordo com a análise descritiva apresentada anteriormente: formato de $\mathrm{U}$ tanto para homens quanto para mulheres, indicando que há uma chance maior de os jovens e de os idosos estarem inativos. Para os homens, a probabilidade mínima de inatividade se dá aos 45 anos, e, para as mulheres, aos 39 anos. 
Gráfico 5_ Impacto da escolaridade sobre o desemprego

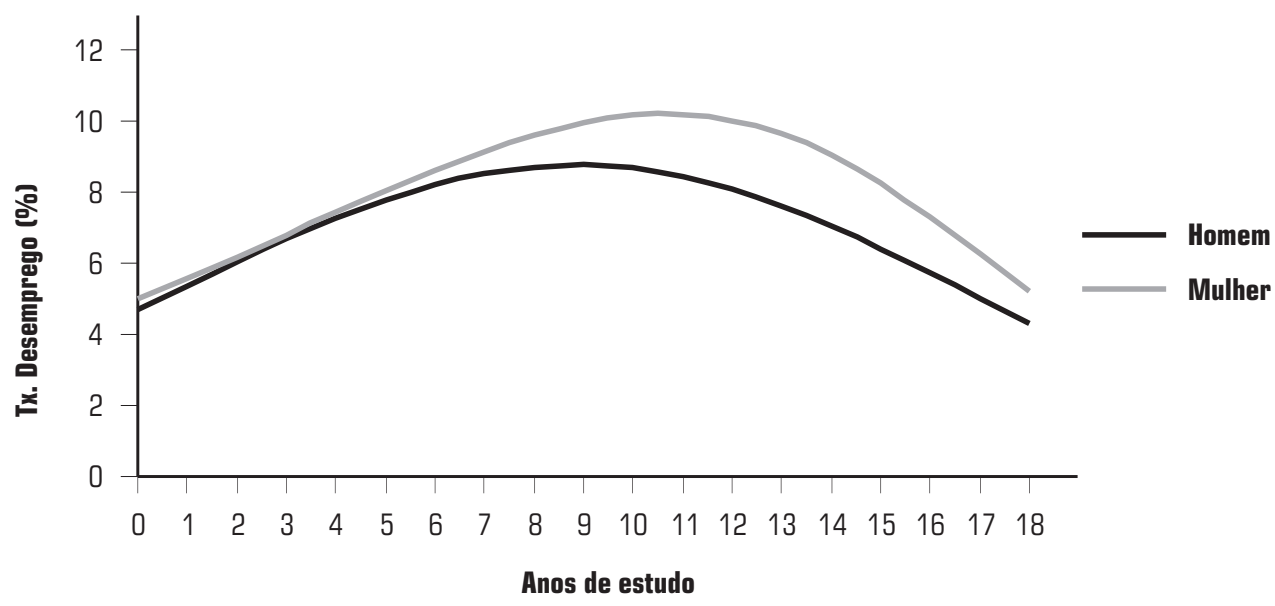

Fonte: Elaboração própria com base nos dados da PNAD 2004 e nas simulações.

\section{Gráfico 6_Impacto da idade sobre a inatividade}

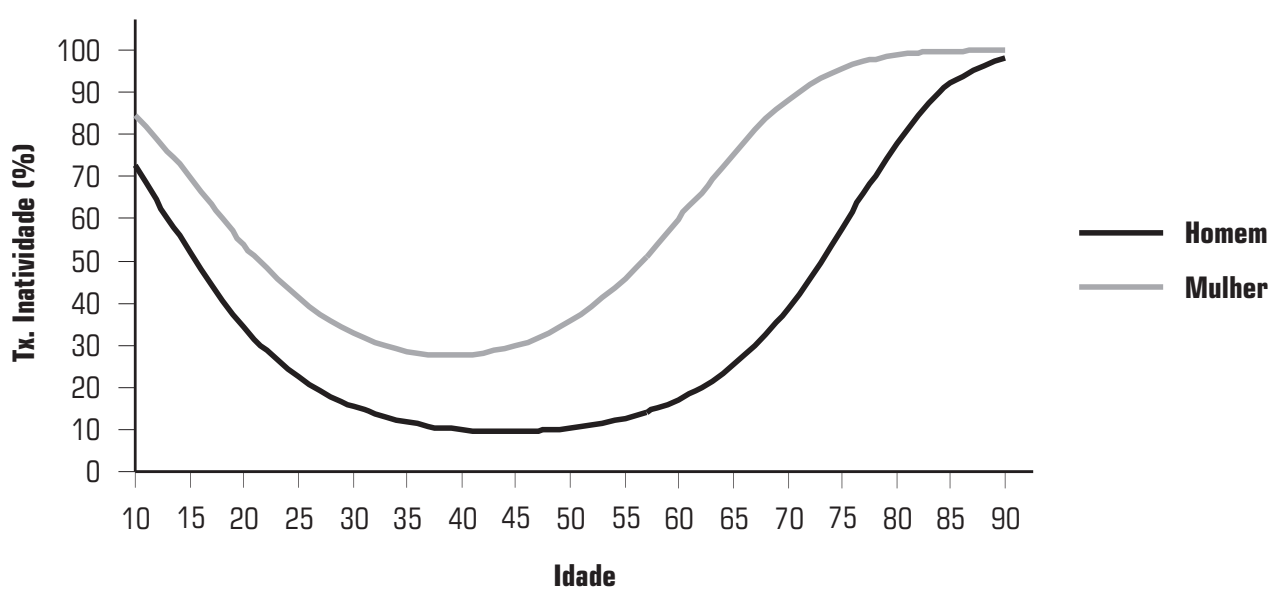

Fonte: Elaboração própria com base nos dados da PNAD 2004 e nas simulações. 
Cabe salientar que a diferença entre os sexos aumenta a partir dos 40 anos, indicando que o comprometimento da mulher com o mercado de trabalho vai se enfraquecendo mais rápido relativamente aos homens (Gráfico 7).

Com relação ao desemprego, a simulação aponta maior probabilidade desse para os mais jovens, atingindo seu máximo para a idade de 28 anos, tendência também apontada em Fernandes e Picchetti (1999). Entretanto, o perfil para mulheres e homens guarda algumas diferenças. Até os 40 anos, a probabilidade entre as mulheres é maior do que a dos homens. Isso se deve, possivelmente, ao fato de que, na idade fértil, há maior disposição por parte dos empregadores em contratar homens, tudo o mais constante, em razão da possibilidade de a mulher se afastar por causa da maternidade. Ou ainda, pelo fato de a mulher ter de conciliar a atividade no mercado de trabalho com aquelas relacionadas ao cuidado com os filhos, elas tendem a preferir postos de trabalho com jornadas mais flexíveis e, assim, acabam demorando mais para encontrar um posto de trabalho com tais características desejáveis.

\section{Gráfico 7_ Impacto da idade sobre o desemprego}

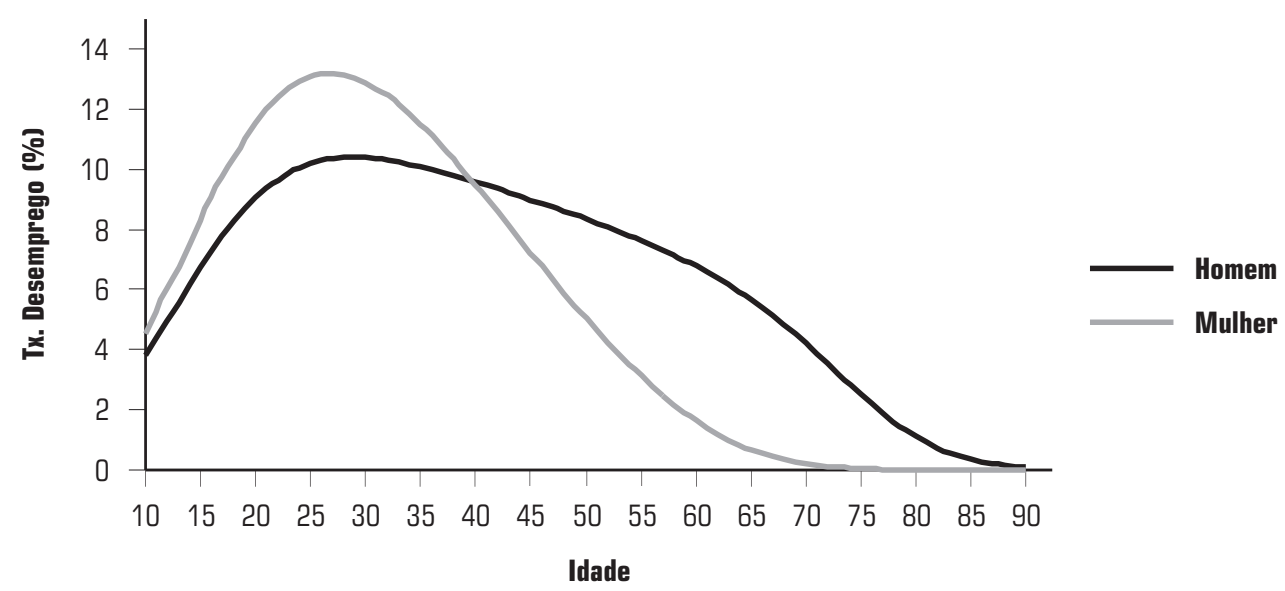

Fonte: Elaboração própria com base nos dados da PNAD 2004 e nas simulações. 
Por outro lado, a rápida queda do desemprego após os 40 anos deve estar ligada à elevada inatividade apontada no Gráfico 3. De acordo com esses resultados, o que parece ocorrer é que, a partir dos 40 anos, apenas as mulheres com maior empregabilidade permanecem no mercado de trabalho.

\subsection{3_Renda domiciliar líquida}

Há uma relação positiva entre a probabilidade de inatividade e a renda domiciliar líquida, resultado esperado com base no modelo teórico de oferta de trabalho. Se lazer é um bem normal, quanto maior a renda do não trabalho (captada pela renda domiciliar líquida), maior é a quantidade desse bem e, portanto, menor a oferta de trabalho do indivíduo. É interessante notar que o impacto da renda líquida sobre a probabilidade de inatividade é maior para as mulheres, indicando que esse fator é mais importante para a decisão feminina (Gráfico 8).

Já a análise do gráfico de probabilidades simuladas de desemprego com relação à renda domiciliar líquida mostra que, quanto maior é essa renda, menor a probabilidade de desemprego dos indivíduos. Novamente, o impacto da renda domiciliar líquida sobre o desemprego é maior para as mulheres do que para os homens. Entretanto, no caso do desemprego, as curvas de homens e mulheres se cruzam: quando as mulheres dispõem de uma renda líquida inferior a $\mathrm{R} \$ 3.000,00$, sua probabilidade de desemprego é maior que a dos homens (Gráfico 9).

\subsection{4_ Número de crianças no domicílio}

Com relação ao número de crianças, fica patente a importância de se analisar em separado homens e mulheres, principalmente no caso da inatividade. Com o aumento do número de crianças no domicílio, a probabilidade de inatividade dos homens cai, e a das mulheres sobe, o que está em linha com o esperado pela teoria de divisão do trabalho familiar, que prevê especialização de um cônjuge no trabalho doméstico e do outro no trabalho remunerado no mercado (Gráfico 10).

Já no que diz respeito ao desemprego, há uma relação positiva entre número de crianças no domicílio e desemprego e, de acordo com o Gráfico 11, é mais pronunciada para as mulheres. No entanto, conforme colocado anteriormente, para homens e mulheres o impacto da variável (em termos do efeito marginal para o indivíduo de características médias) não foi estatisticamente significativo. 
Gráfico 8_ Impacto da renda domiciliar líquida sobre a inatividade

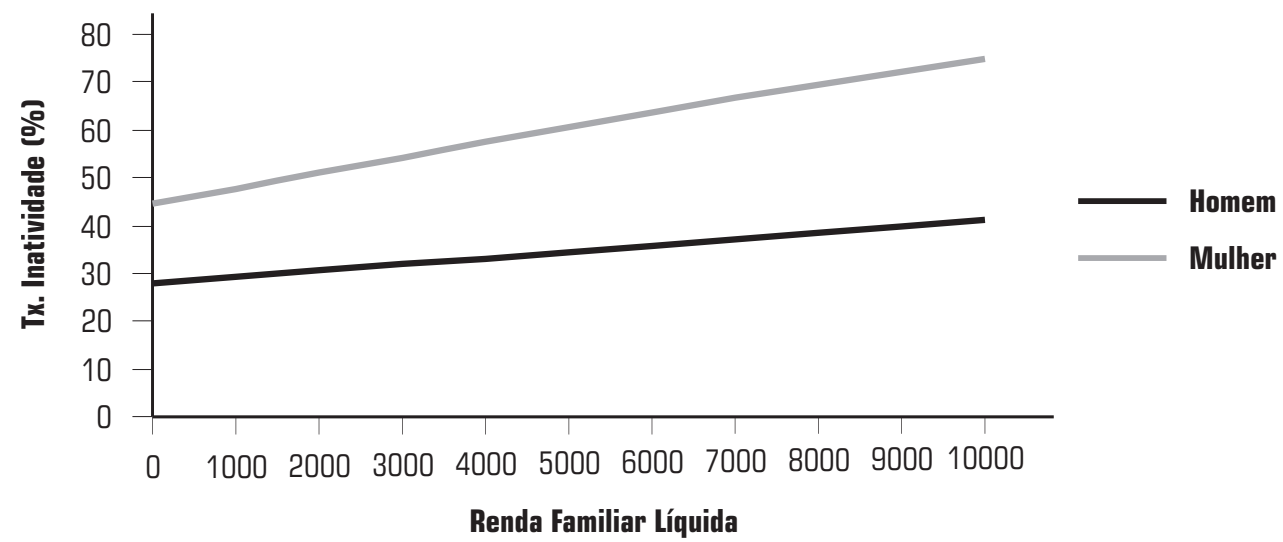

Fonte: Elaboração própria com base nos dados da PNAD 2004 e nas simulações.

Gráfico 9_Impacto da renda domiciliar líquida sobre o desemprego

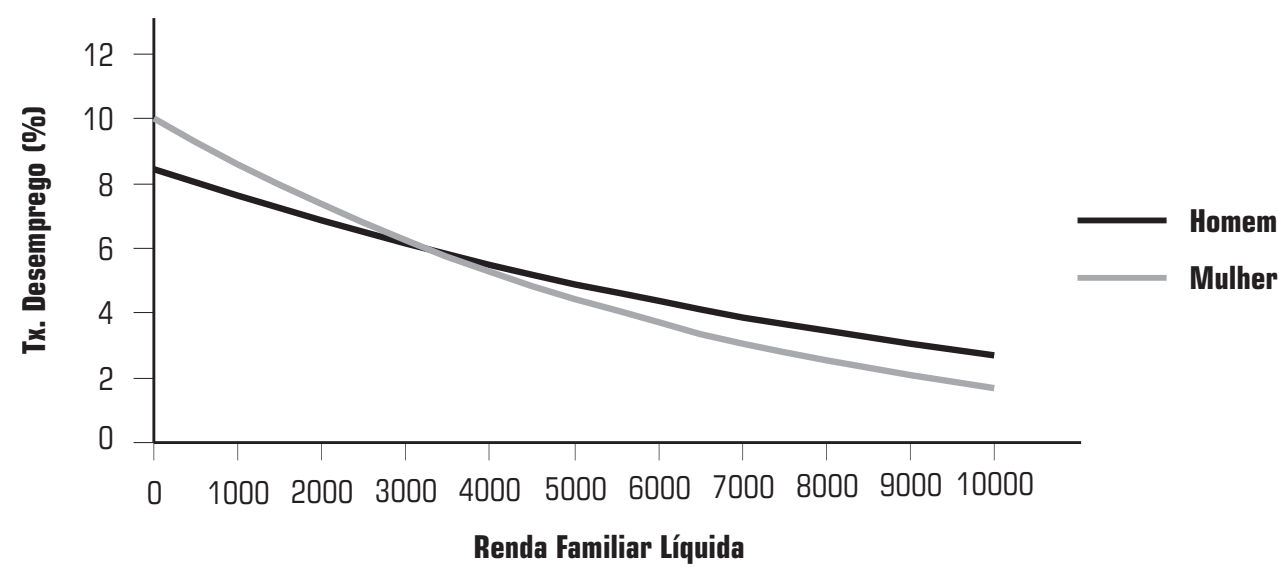

Fonte: Elaboração própria com base nos dados da PNAD 2004 e nas simulações. 


\section{Gráfico 10_Impacto do número de crianças sobre a inatividade}

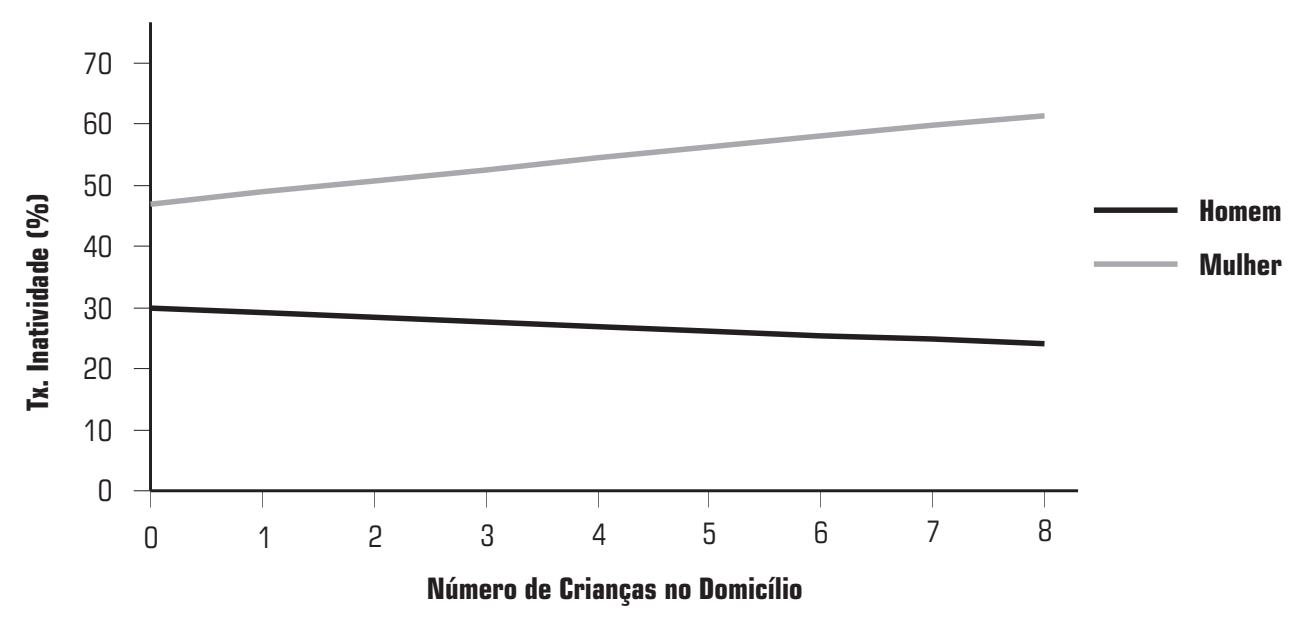

Fonte: Elaboração própria com base nos dados da PNAD 2004 e nas simulações.

\section{Gráfico 11_ Impacto do número de crianças sobre o desemprego}

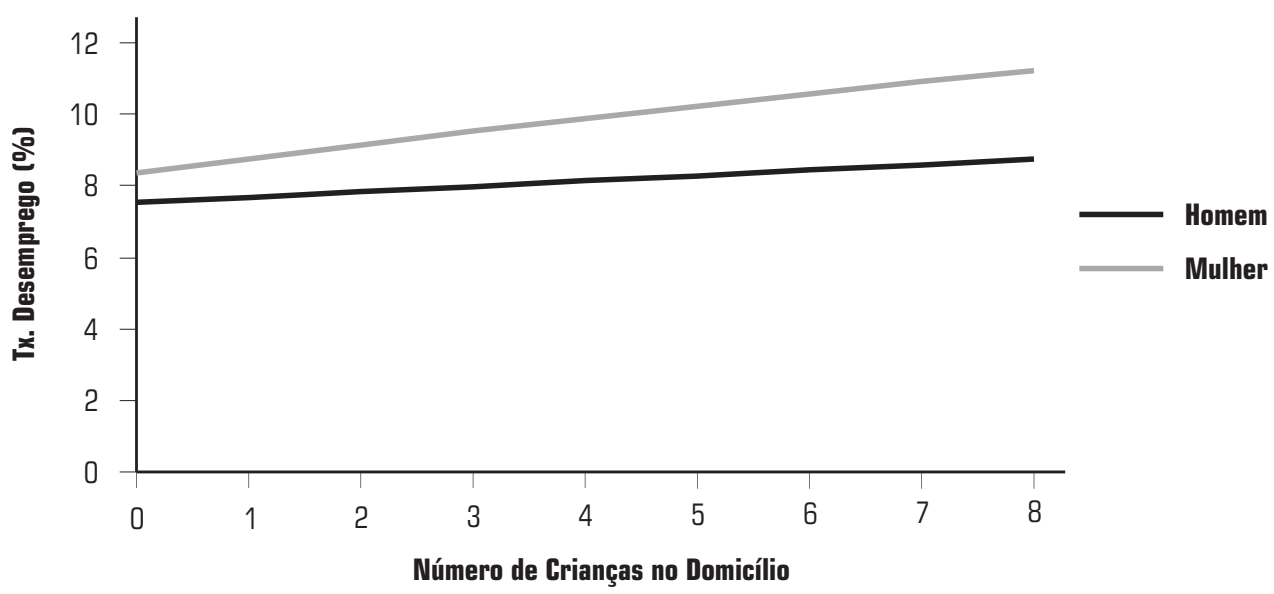

Fonte: Elaboração própria com base nos dados da PNAD 2004 e nas simulações. 


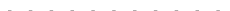

6 O valor de $\mathrm{R} \$ 150,00$ foi adotado por ser amplamente utilizado nos programas sociais do governo brasileiro como linha de pobreza.
No caso da inatividade para as mulheres, pode-se pensar que dois efeitos estão de fato atuando: de um lado, a questão cultural da permanência de mulheres em casa para o cuidado dos filhos; e, de outro, a necessidade maior de mulheres de baixa renda, muitas vezes chefes de família, de sair de casa à procura de trabalho para ajudar no sustento da família. Em termos "líquidos", de acordo com os resultados obtidos, o primeiro efeito prepondera. No entanto, procurando melhor entendimento acerca do efeito do número de crianças sobre a inatividade, optou-se por estimar dois modelos separados: um para as mulheres com renda domi- ciliar per capita superior a $\mathbf{R} \$ 150,00$ (não pobres) e outro para as mulheres com renda inferior ou igual a $\mathrm{R} \$ 150,00$ (pobres) $^{6}$ (Gráfico 12).

Como esperado, os resultados para inatividade são bastante diferentes para mulheres pobres e não pobres. Um primeiro ponto é que, para as mulheres sem filhos, a inatividade das pobres é significativamente maior que a das não pobres. Provavelmente, o que explica esse resultado é a diferença de custo de oportunidade de cada grupo, visto que mulheres não pobres possuem escolaridade mais elevada que as demais. É importante destacar, por outro lado, que o

\section{Gráfico 12_Impacto do número de crianças sobre a inatividade de mulheres pobres e não pobres}

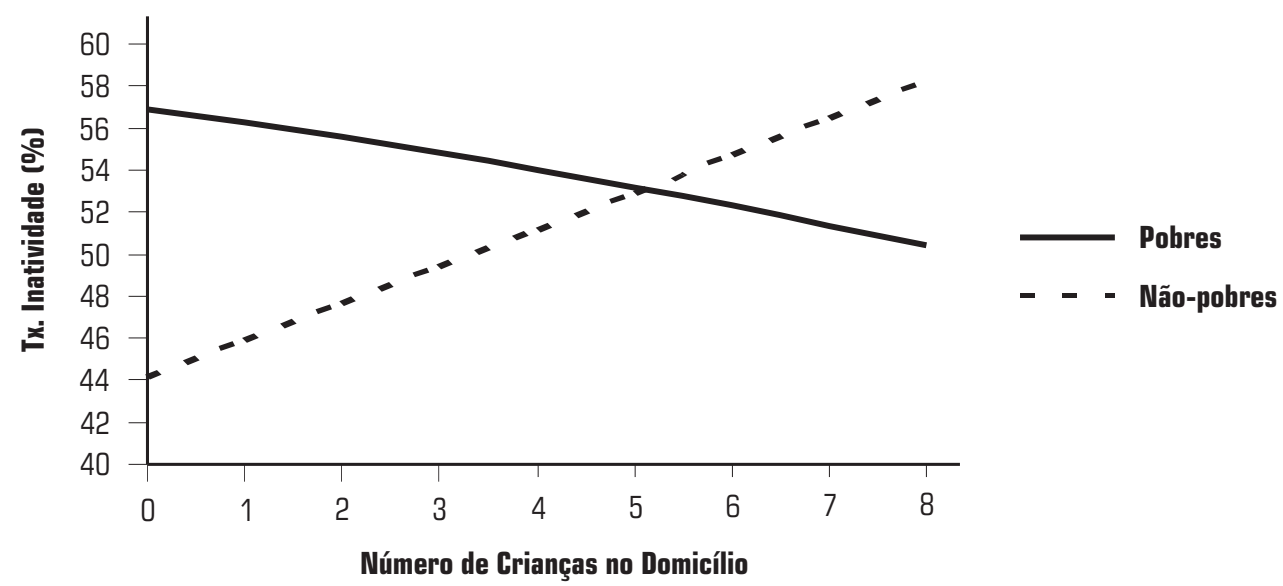

Fonte: Elaboração própria com base nos dados da PNAD 2004 e nas simulações. 
fato de a inatividade para as mulheres com 2 filhos, por exemplo, ser também significativamente maior para aquelas de renda baixa deve ser explicado pelo argumento anterior, mas também pela dificuldade que essas mulheres enfrentam para conseguir arranjar alguém que cuide de seus filhos (child care).

Um segundo ponto é que, enquanto a probabilidade de inatividade das mulheres pobres cai pouco com o aumento do número de crianças, para as mulheres não pobres a probabilidade aumenta. A partir de seis crianças no domicílio, a probabilidade de inatividade das não pobres passa a ser maior do que a das pobres. Para as não pobres, isso pode estar refletindo preferências de fato: essas mulheres preferem cuidar dos filhos a trabalhar. Para as pobres, pode significar arrumar alguém para cuidar dos filhos, visto que os irmãos mais velhos podem vir a fazer esse papel. Além do que, com um número maior de crianças, deve aumentar a necessidade de a mulher entrar no mercado de trabalho para ajudar na complementação da renda familiar.

O mesmo exercício também foi feito para a variável "desemprego", e, também nesse caso, os resultados são bastante diferentes para os dois grupos de mulheres. A probabilidade de desemprego entre as mulheres não pobres se altera muito pouco com o número de crianças. Já para o grupo das mulheres pobres, a probabilidade de desemprego daquelas sem crianças no domicílio é quase três vezes maior que a das não pobres. Além disso, há uma relação inversa entre a probabilidade de desemprego e o número de crianças no domicílio. Isso provavelmente reflete o fato de que, com maior número de filhos, o salário de reserva deve ir caindo, fazendo com que as mulheres mais pobres estejam dispostas a aceitar uma ocupação com mais facilidade do que o fariam se tivessem menos filhos (Gráfico 13).

\subsubsection{Número de adultos no domicílio}

As mulheres têm probabilidade maior de estar inativas do que os homens, para qualquer número de adultos no domićlio, o que é esperado, dado maior engajamento masculino no mercado de trabalho.

Observa-se uma queda na taxa de inatividade tanto de homens quanto de mulheres entre 1995 e 2004. Entretanto, a probabilidade de inatividade de homens, em razão do número de adultos no domicílio, aumentou com relação a 1995 . Ao mesmo tempo, a probabilidade de inatividade das mulheres caiu, refletindo a manutenção da tendência de aumento da participação feminina no mercado de trabalho desde a década de oitenta (Gráfico 14). 
Gráfico 13_ Impacto do número de crianças sobre o desemprego de mulheres pobres e não pobres

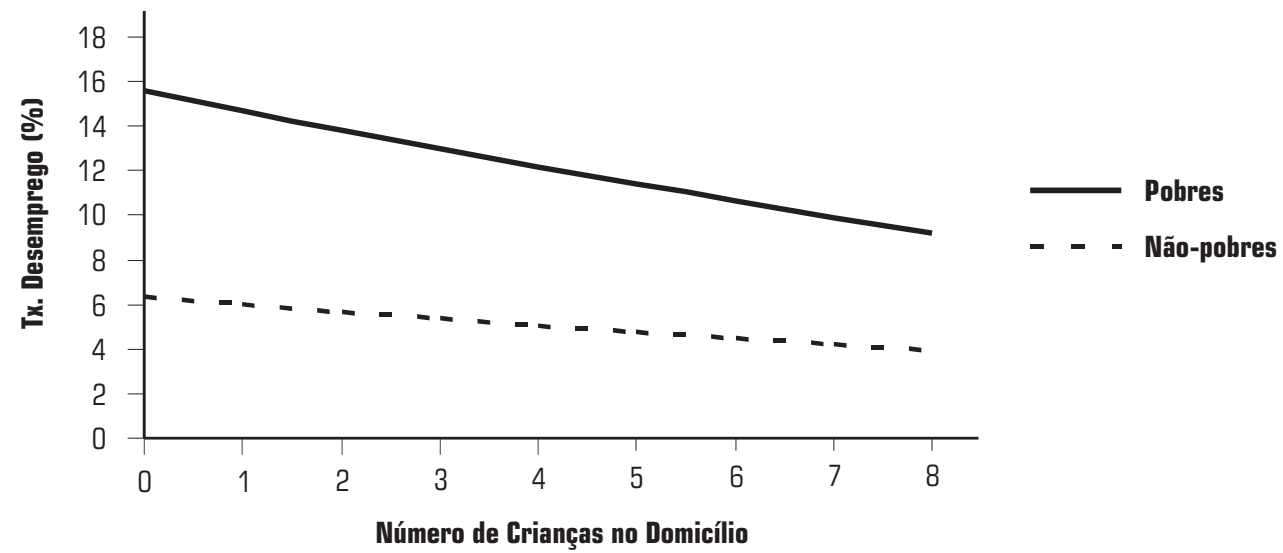

Fonte: Elaboração própria com base nos dados da PNAD 2004 e nas simulações.

Gráfico 14_Impacto do número de adultos sobre a inatividade

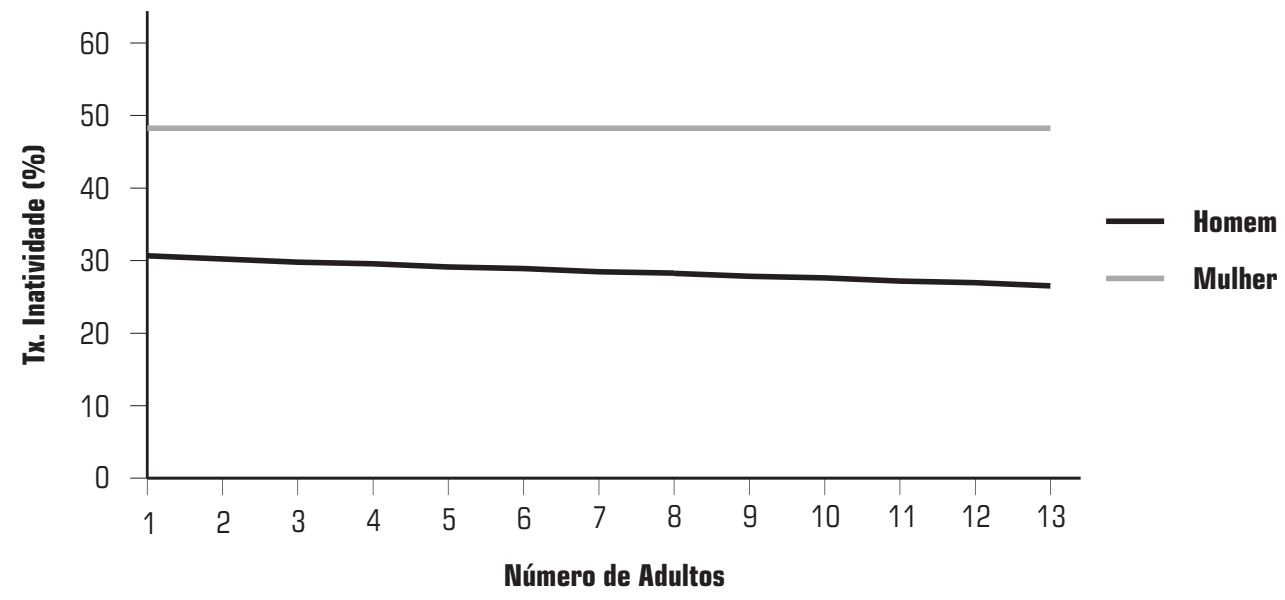


Quanto ao desemprego, homens e mulheres apresentaram um padrão parecido, como se vê no Gráfico 15. Em comparação aos dados de 1995, entretanto, o comportamento no caso dos homens é diferenciado. Em 1995, a probabilidade de desemprego masculino possuía relação mais forte com o número de adultos do que a encontrada em 2004.

\subsection{6_Raça}

O primeiro fato que chama a atenção nessa simulação é que os brancos possuem as menores probabilidades de desemprego e as maiores de inatividade. Assim, fica claro que negros e pardos, seja homens, seja mulheres, procuram maior inserção no mercado, mesmo que tenham menos chance de conseguir uma ocupação. Outro ponto importante é que o diferencial de inatividade entre os sexos é bastante grande, sendo maior entre mulheres brancas e homens brancos do que entre mulheres negras e homens negros (Gráfico 16).

Com relação ao desemprego, para cada raça, observa-se que as mulheres têm probabilidade de desemprego maior que os homens. Também se nota que a diferença entre a probabilidade de desemprego entre homens e mulheres negras é de 0,3 pontos percentuais, enquanto entre homens e mulheres pardos é de 1,3 p.p., e entre homens e mulheres brancos é de 1,0 ponto percentual (Gráfico 17).

\section{Gráfico 15_ Impacto do número de adultos sobre o desemprego}

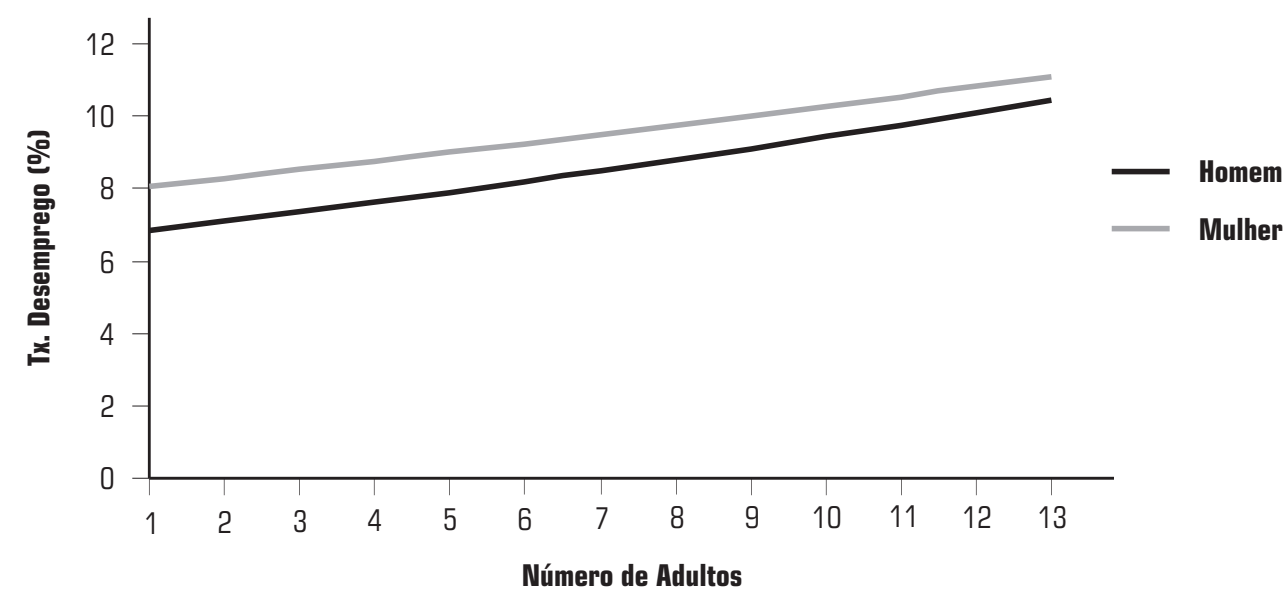

Fonte: Elaboração própria com base nos dados da PNAD 2004 e nas simulações. 
Gráfico 16_Probabilidade de inatividade por cor da pele

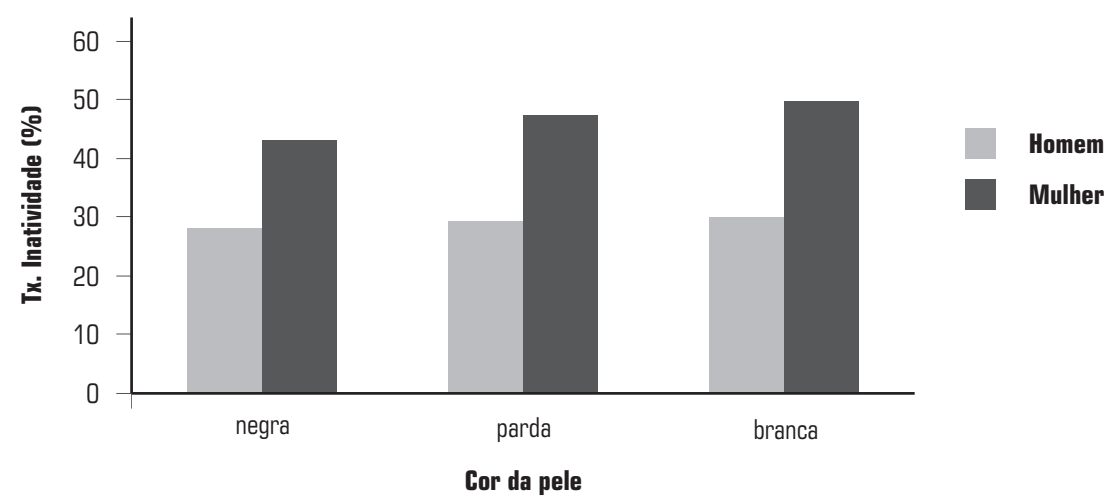

Fonte: Elaboração própria com base nos dados da PNAD 2004 e nas simulações.

Gráfico 11_Probabilidade de desemprego por cor da pele

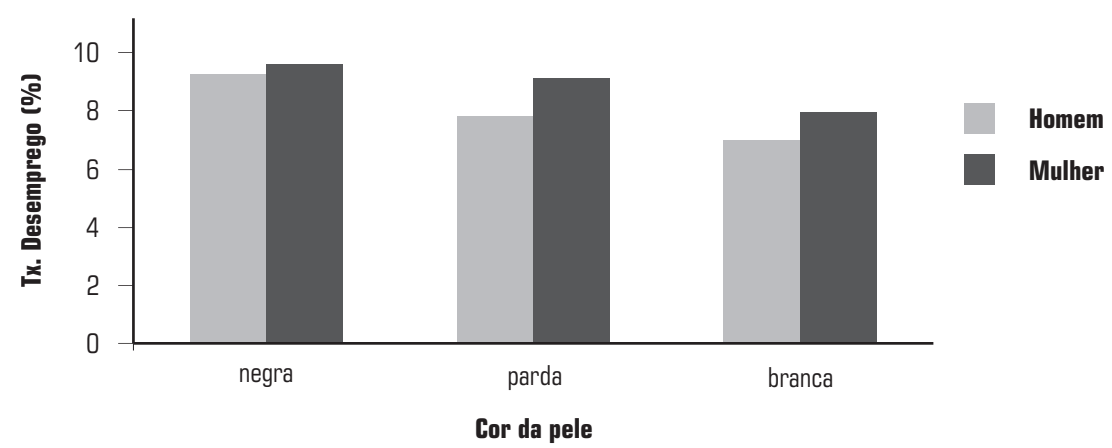

Fonte: Elaboração própria com base nos dados da PNAD 2004 e nas simulações. 


\section{4_Conclusões}

A evolução da estrutura do desemprego e da inatividade nas regiões metropolitanas, no período entre 1995 e 2004, mostrou resultados interessantes. Para o total da população, as mudanças na estrutura do desemprego e da inatividade podem ser sumarizadas num quadro em que a probabilidade de inatividade manteve-se nos mesmos padrões observados em 1995, enquanto a de desemprego teve aumento significativo em praticamente todas as dimensões consideradas.

No entanto, o aspecto que mais chama a atenção são as diferenças entre homens e mulheres nas probabilidades de desemprego e inatividade. Como esperado, nas simulações, as mulheres apresentam probabilidade de inatividade maior que os homens em todas as variáveis analisadas. Para o desemprego, a situação relativa dos homens e mulheres depende da variável considerada.

No caso de educação, como esperado, há uma relação inversa entre anos de estudo e inatividade tanto para homens quanto para mulheres. No caso do desemprego, para ambos os grupos encontramos uma relação em forma de $U$ invertido, mas o interessante é que, até quatro anos de estudo, a probabilidade de desemprego é similar para homens e mulheres. A partir daí, a probabilidade passa a ser sempre maior para as mulheres. Essa dinâmica do desemprego e da inatividade reflete, provavelmente, o fato de que, para baixos níveis de escolaridade, a maioria das mulheres prefere ficar na inatividade (até quatro anos de estudo a probabilidade de inatividade é de $60 \%$ para as mulheres). Por sua vez, as que entram no mercado de trabalho o fazem quase que a qualquer preço, estando assim, dispostas a assumir uma ocupação mais precária, o que leva ao baixo desemprego delas. Com o aumento da escolaridade, a trajetória do desemprego e da inatividade das mulheres passa a ser muito parecida com a dos homens, sendo que tais probabilidades são sempre maiores para as mulheres.

No que se refere à idade, até aproximadamente os 45 anos, a probabilidade de desemprego das mulheres é maior que a dos homens, invertendo-se a partir de então, o que é explicado pelo forte crescimento da inatividade a partir dessa idade. Ou seja, essa é uma idade crítica em que parte das mulheres decide continuar trabalhando enquanto as demais abandonam o mercado de trabalho.

Em termos de inatividade, as respostas de homens e mulheres à variável "número de crianças no domicílio" são opostas: positiva para mulheres e negativa para homens, um resultado esperado tendo em vista a divisão tradicional de tarefas 
dentro do lar. Entretanto, nem todas as mulheres apresentam o mesmo padrão de comportamento. Em particular, para as mulheres pobres, a inatividade diminui com o número de crianças, refletindo a maior necessidade de entrada no mercado para complementação da renda familiar. Para o desemprego, a trajetória para homens e mulheres é similar.

Com relação à inatividade por raça, tanto para homens como para mulheres, a inatividade dos negros é maior que a dos brancos e pardos. Em termos de desemprego, o resultado é o inverso, ou seja, as taxas são mais elevadas para os negros. Esse conjunto de resultados pode ser reflexo tanto de um comportamento discriminador contra os negros no mercado de trabalho (visto que diversas características produtivas estão sendo consideradas na análise) quanto de não estarmos incorporando na análise características não observáveis que afetem diferentemente as probabilidades de desemprego e de inatividade de indivíduos brancos, pardos e negros. Infelizmente, esta análise não permite identificar explicitamente o peso de cada um desses componentes no resultado.

No atual contexto de aumento de participação feminina, em que diversas políticas direcionadas às mulheres têm sido implementadas (ampliação da licença-ma- ternidade para 180 dias, desconto no IRPF da parcela do empregador no INSS dos empregados domésticos), é de suma importância conhecer os determinantes do desemprego e da entrada da mulher no mercado de trabalho. Em termos de políticas que incentivem a participação das mulheres no mercado e a redução do desemprego delas, podemos citar um estímulo à escolarização, se possível, além do ensino médio, quando as taxas de desemprego tendem a cair de forma considerável. Além disso, uma política de acesso mais amplo a creches, focada nos filhos das mulheres mais pobres, contribuiria para a redução da elevada inatividade desse grupo, permitindo sua entrada no mercado de trabalho. Isso contribuiria para a geração da renda familiar e, eventualmente, para a saída da família da situação de pobreza. 


\section{Referências bibliográficas}

BARROS, R.; CAMARGO, J. M.; MENDONÇA, R. Estrutura do desemprego no Brasil. IPEA, 1997. (Texto para discussão, 478)

BARROS, R. P.; CORSEUIL, C. H.; LEITE, P. G. Labor market and poverty in Brazil. Revista de Econometria, v. 19, n. 2, 1999.

BIVAR, W. Estimativas da duração média do desemprego no Brasil. Pesquisa e Planejamento Econômico, v. 23, n. 2, 1991.

CAMARGO, J.; REIS, M.

Desemprego: o custo da desinformação. Revista Brasileira de Economia, v. 59, n. 3 , p. 381-425, 2005.

FERNANDES, R.; PAZELLO, E. T.; FELICIO, F. A importância da estrutura familiar e do engajamento no mercado de trabalho na determinação da pobreza no Brasil. Pesquisa e Planejamento Econômico, v. 32, n. 2, p. 233-250, 2002.

FERNANDES, R.; PICCHETTI, P. Uma análise da estrutura do desemprego e da inatividade no Brasil metropolitano. Pesquisa e Planejamento Econômico, v. 29, n. 1, p. 87-112, 1999.
FERREIRA, F.; BARROS, R. P. The slippery slope: explaining the increase in extreme poverty in urban Brazil, 1976-1996. Revista de Econometria, v. 19, n. 2, 1999.

FLORI, P. Desemprego de jovens: um estudo sobre a dinâmica do mercado de trabalho juvenil brasileiro. 2003. Dissertação (Mestrado em Economia) Faculdade de Economia, Administração e Contabilidade, Universidade de São Paulo, FEA-USP, São Paulo, 2003.

HAMERMESH, D. Replication in economics. Canadian Journal of Economics, v. 40, n. 3, p. 715-733, 2007.

MENEZES-FILHO, N.; PICCHETTI, P. Os determinantes da duração do desemprego em São Paulo. Pesquisa e Planejamento Econômico, v. 30, n. 1, p. 23-48, 2000.

\section{MENEZES-FILHO, N.} PICCHETTI, P. Os

determinantes da duração do desemprego no Brasil metropolitano: 1984-1998. In: CHAHAD, J.; MENEZESFILHO, N. (Orgs.). Mercado de trabalho no Brasil: salário, emprego e desemprego numa era de grandes mudanças. São Paulo: LTr, 2002. p. 55-79.
MELLO, L.; MENEZES-FILHO, N.; SCORZAFAVE, L. Improving labour utilisation in Brazil. 2006.

(OECD Economics Department Working Paper, n. 533). Disponível em: <http://www.oecd.org/eco/ working_papers $>$.

REIS, M. Os impactos das mudanças na demanda por trabalho qualificado sobre o desemprego por nível de qualificação durante os anos noventa no Brasil. Revista Brasileira de Economia, v. 60, n. 3 , p. 297-319, 2006

REIS, M.; CAMARGO, J. M.

Desemprego dos jovens no Brasil: os efeitos da estabilização da inflação em um mercado de trabalho com escassez de informação. Revista Brasileira de Economia, v. 61, p. 493-518, 2007.

SCORZAFAVE, L. G.; MENEZES-FILHO, N.

Participação feminina no mercado de trabalho brasileiro: evolução e determinantes. Pesquisa e Planejamento Econômico, v. 31, n. 3, p. 441-477, 2001.

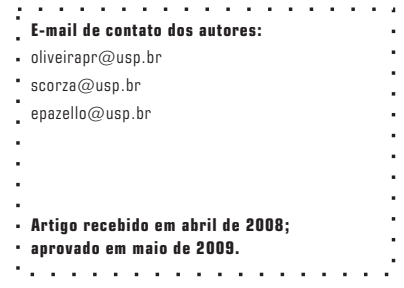


Apêndice

\section{Saída do logit multinomial para as mulheres}

Multinomial logistic regression

Number of obs $=57066$ Wald $\mathrm{X}^{2}(42)=8131.55$

Prob $>\mathrm{X}^{2}=0.0000$

Log-pseudolikelihood $=-41154.458$

Pseudo $\mathrm{R}^{2}=0.2192$

\begin{tabular}{|c|c|c|c|c|c|c|c|c|c|c|c|c|}
\hline $\begin{array}{l}\text { Robust } \\
\text { depend }\end{array}$ & Coef. & $\begin{array}{l}\text { Std. } \\
\text { Err. }\end{array}$ & $\mathbf{z}$ & $P>|z|$ & \multicolumn{2}{|c|}{ [95\% Conf. Interval] } & Coef. & $\begin{array}{l}\text { Std. } \\
\text { Err. }\end{array}$ & $z$ & $P>|z|$ & \multicolumn{2}{|c|}{ [95\% Conf. Interval] } \\
\hline \multicolumn{7}{|l|}{ inatividade } & \multicolumn{6}{|c|}{ desemprego } \\
\hline anoest & .0452642 & .0123797 & 3.66 & 0.000 & .0210004 & .069528 & .1498039 & .0210486 & 7.12 & 0.000 & .1085495 & .1910584 \\
\hline anoest $^{2}$ & -.0136618 & .0008927 & -15.30 & 0.000 & -.0154114 & -.0119122 & -.0115363 & .0012364 & -9.33 & 0.000 & -.0139596 & -.0091131 \\
\hline idade & -.2917388 & .0057987 & -50.31 & 0.000 & -.3031041 & -.2803736 & -.0119791 & .0111707 & -1.07 & 0.284 & -.0338734 & .0099151 \\
\hline rendaliq & .0001694 & .0000186 & 9.10 & 0.000 & .000133 & .0002059 & -.0001013 & .000024 & -4.23 & 0.000 & -.0001484 & -.0000543 \\
\hline ncrianças & .1303521 & .0153423 & 8.50 & 0.000 & .1002816 & .1604225 & .1085703 & .022082 & 4.92 & 0.000 & .0652904 & .1518502 \\
\hline nadultos & .0070753 & .0091624 & 0.77 & 0.440 & -.0108826 & .0250332 & .0343408 & .0130109 & 2.64 & 0.008 & .00884 & .0598417 \\
\hline pardo & -.1204795 & .0299522 & -4.02 & 0.000 & -.1791848 & -.0617743 & .0993664 & .0459149 & 2.16 & 0.030 & .0093749 & .1893579 \\
\hline negro & -.3762866 & .049287 & -7.63 & 0.000 & -.4728873 & -.2796859 & .0563513 & .0686951 & 0.82 & 0.412 & -.0782886 & .1909911 \\
\hline cônjuge & .7866814 & .0361734 & 21.75 & 0.000 & .7157827 & .85758 & -.0144394 & .0534415 & -0.27 & 0.787 & -.1191828 & .090304 \\
\hline outracond & .2989151 & .0673024 & 4.44 & 0.000 & .1670047 & .4308254 & .2446659 & .0961118 & 2.55 & 0.011 & .0562902 & .4330415 \\
\hline aposent & 1.128 .737 & .0745904 & 15.13 & 0.000 & .9825424 & 1.274 .931 & -.1625169 & .2441328 & -0.67 & 0.506 & -.6410084 & .3159746 \\
\hline Belém & .1629985 & .0467707 & 3.49 & 0.000 & .0713297 & .2546673 & -.3523861 & .073482 & -4.80 & 0.000 & -.496408 & -.2083641 \\
\hline Fortaleza & .1646686 & .0426332 & 3.86 & 0.000 & .0811092 & .2482281 & -.2706992 & .0665266 & -4.07 & 0.000 & -.4010889 & -.1403096 \\
\hline Recife & .499916 & .0412505 & 12.12 & 0.000 & .4190666 & .5807654 & .2603591 & .0603301 & 4.32 & 0.000 & .1421143 & .3786039 \\
\hline Salvador & -.1106597 & .043794 & -2.53 & 0.012 & -.1964944 & -.024825 & .2720365 & .0595587 & 4.57 & 0.000 & .1553037 & .3887694 \\
\hline Belo Horizonte & -.2834709 & .0449548 & -6.31 & 0.000 & -.3715807 & -.1953611 & -.257806 & .0671437 & -3.84 & 0.000 & -.3894052 & -.1262067 \\
\hline Rio de Janeiro & .2155774 & .0397819 & 5.42 & 0.000 & .1376064 & .2935485 & -.0558056 & .0626057 & -0.89 & 0.373 & -.1785105 & .0668994 \\
\hline Curitiba & -.3291143 & .0518854 & -6.34 & 0.000 & -.4308078 & -.2274208 & -.6644055 & .090556 & -7.34 & 0.000 & -.841892 & -.4869189 \\
\hline Porto Alegre & -.316222 & .0393211 & -8.04 & 0.000 & -.3932899 & -.2391541 & -.3902313 & .0634004 & -6.16 & 0.000 & -.5144938 & -.2659689 \\
\hline constante & 4,735746 & .1172471 & 40.39 & 0.000 & 4,50595 & 4,965546 & $-1,0424$ & .2005977 & -5.20 & 0.000 . & $-1,4355$ & -6492204 \\
\hline
\end{tabular}

(empregado é a categoria base) 


\section{Efeitos marginais}

Se $y=\operatorname{Pr}$ (inativo) $($ predict, $\mathrm{p}$ outcome $($ inativo $))=0,54413428$

Se $y=\operatorname{Pr}($ desempregado $)($ predict, $\mathrm{p}$ outcome $($ desempregado $))=0,05380597$

\begin{tabular}{|c|c|c|c|c|c|c|c|c|c|c|c|c|c|c|}
\hline ble & $d y / d x$ & $\begin{array}{l}\text { Std. } \\
\text { Err. }\end{array}$ & $z$ & $P>|z|$ & [95\% & C.I.] & X & $d y / d x$ & $\begin{array}{l}\text { Std. } \\
\text { Err. }\end{array}$ & $\mathbf{z}$ & $P>|z|$ & [95\% & C.I.] & X \\
\hline \multicolumn{8}{|l|}{ inatividade } & \multicolumn{7}{|c|}{ desemprego } \\
\hline anoest & .006842 & .00301 & 2.27 & 0.023 & .00094 & .012744 & 76.084 & .0063014 & .00106 & 5.94 & 0.000 & .004224 & .008379 & 76.084 \\
\hline anoest $^{2}$ & -.0030511 & .00022 & -14.00 & 0.000 & -.003478 & -.002624 & 761.964 & -.0001873 & .00006 & -2.99 & 0.003 & -.00031 & -.000064 & 761.964 \\
\hline idade & -.0720157 & .00134 & -53.56 & 0.000 & -.074651 & -.06938 & 37.046 & .0079316 & .00042 & 19.06 & 0.000 & .007116 & .008747 & 37.046 \\
\hline rendaliq & .000045 & .00000 & 10.16 & 0.000 & .000036 & .000054 & 1374.17 & -.0000101 & .00000 & -8.49 & 0.000 & -.000012 & $-7.8 \mathrm{e}-06$ & 1374.17 \\
\hline ncrianças & .0291554 & .00361 & 8.08 & 0.000 & .022085 & .036226 & .588637 & .001711 & .00105 & 1.63 & 0.103 & -.000346 & .003768 & .588637 \\
\hline nadultos & .0007496 & .00217 & 0.35 & 0.730 & -.0035 & .004999 & 338.406 & .0015412 & .00062 & 2.47 & 0.013 & .00032 & .002763 & 338.406 \\
\hline pardo* & -.0328756 & .00714 & -4.60 & 0.000 & -.046876 & -.018875 & .351649 & .0087555 & .00235 & 3.72 & 0.000 & .004143 & .013368 & .351649 \\
\hline negro* & -.0954706 & .01177 & -8.11 & 0.000 & -.118545 & -.072396 & .082916 & .0144679 & .00408 & 3.54 & 0.000 & .006468 & .022468 & .082916 \\
\hline filho* & .0944257 & .01207 & 7.82 & 0.000 & .07076 & 118091 & .274648 & .0045704 & .0036 & 1.27 & 0.204 & -.002489 & .011629 & .274648 \\
\hline cônjuge* & .1917262 & .00829 & 23.12 & 0.000 & .175475 & .207977 & .409626 & -.0232654 & .00262 & -8.89 & 0.000 & -.028396 & -.018134 & .409626 \\
\hline outracond* & .0652731 & .01544 & 4.23 & 0.000 & .035019 & .095527 & .061777 & .0033051 & .00494 & 0.67 & 0.504 & -.006383 & .012993 & .061777 \\
\hline aposent* & .2530081 & .01372 & 18.44 & 0.000 & .226116 & .2799 & .081418 & -.0338446 & .0061 & -5.55 & 0.000 & -.045806 & -.021883 & .081418 \\
\hline Belém* & .0488448 & .01097 & 4.45 & 0.000 & .027343 & .070346 & .036285 & -.0190642 & .00265 & -7.19 & 0.000 & -.024261 & -.013867 & .036285 \\
\hline Fortaleza & .0475152 & .01 & 4.75 & 0.000 & .027909 & .067121 & .060685 & -.0162729 & .00258 & -6.30 & 0.000 & -.021334 & -.011212 & .060685 \\
\hline Recife* & .1119598 & .00907 & 12.34 & 0.000 & .094174 & .129746 & .06732 & -.002626 & .00281 & -0.94 & 0.350 & -.008128 & .002876 & .06732 \\
\hline Salvador & -.0364639 & .01043 & -3.50 & 0.000 & -.056897 & -.016031 & .060556 & .0194422 & .00369 & 5.27 & 0.000 & .012209 & .026676 & .060556 \\
\hline Belo Horizonte* & -.0637659 & .01086 & -5.87 & 0.000 & -.08506 & -.042471 & .086831 & -.0050453 & .00307 & -1.64 & 0.100 & -.011059 & .000969 & .086831 \\
\hline Rio de Janeiro* & .0546693 & .00934 & 5.85 & 0.000 & .036367 & .072972 & .213946 & -.0088912 & .00281 & -3.16 & 0.002 & -.014405 & -.003378 & .213946 \\
\hline Curitiba* & -.0668636 & .01266 & -5.28 & 0.000 & -.091677 & -.04205 & .056449 & -.0205393 & .0032 & -6.43 & 0.000 & -.026803 & -.014275 & .056449 \\
\hline Porto Alegre* & -.0689062 & .00951 & -7.24 & 0.000 & -.087548 & -.050265 & .075121 & -.0102583 & .00273 & -3.76 & 0.000 & -.015602 & -.004915 & .075121 \\
\hline
\end{tabular}

$\left.{ }^{*}\right)$ dy/dx é para uma mudança discreta da varíavel dummy de 0 para 1. 


\section{Saída do logit multinomial para homens}

Multinomial logistic regression

Number of obs $=50310$ Wald $X^{2}(42)=9194.54$

Prob $>X^{2}=0.0000$

Log-pseudolikelihood $=-27375.656$

Pseudo $\mathrm{R}^{2}=0.3593$

\begin{tabular}{|c|c|c|c|c|c|c|c|c|c|c|c|c|}
\hline $\begin{array}{l}\text { Robust } \\
\text { depend }\end{array}$ & Coef. & $\begin{array}{l}\text { Std. } \\
\text { Err. }\end{array}$ & $z$ & $P>|z|$ & [95\% Con & Interval] & Coef. & $\begin{array}{l}\text { Std. } \\
\text { Err. }\end{array}$ & $\mathbf{z}$ & $P>|z|$ & [95\% Con & Interval] \\
\hline \multicolumn{7}{|l|}{ inatividade } & \multicolumn{6}{|c|}{ desemprego } \\
\hline anoest & -.1371721 & .0180791 & -7.59 & 0.000 & -.1726066 & -.1017377 & .0991275 & .0224355 & 4.42 & 0.000 & .0551547 & .1431002 \\
\hline anoest $^{2}$ & -.0021755 & .0012913 & -1.68 & 0.092 & -.0047064 & .0003555 & -.0085252 & .0014008 & -6.09 & 0.000 & -.0112707 & -.0057796 \\
\hline idade & -.3298785 & .0069326 & -47.58 & 0.000 & -.343466 & -.3162909 & -.0312405 & .0086231 & -3.62 & 0.000 & -.0481415 & -.0143395 \\
\hline rendaliq & .0001092 & .0000213 & 5.13 & 0.000 & .0000675 & .0001509 & -.0000886 & .0000227 & -3.89 & 0.000 & -.0001331 & -.000044 \\
\hline ncrianças & -.0743294 & .0219583 & -3.39 & 0.001 & -.1173669 & -.0312919 & .001271 & .0264539 & 0.05 & 0.962 & -.0505777 & .0531197 \\
\hline nadultos & -.0261811 & .0124144 & -2.11 & 0.035 & -.0505128 & -.0018493 & .0332815 & .0145781 & 2.28 & 0.022 & .0047089 & .0618542 \\
\hline pardo & -.0431178 & .0399867 & -1.08 & 0.281 & -.1214903 & .0352547 & .1075278 & .0509959 & 2.11 & 0.035 & .0075777 & .207478 \\
\hline negro & -.1317231 & .0656475 & -2.01 & 0.045 & -.2603899 & -.0030564 & .2809627 & .0755706 & 3.72 & 0.000 & .1328471 & .4290783 \\
\hline filho & 1,52847 & .0654226 & 23.36 & 0.000 & 1,40024 & 1,65669 & 1,3901 & .0657956 & 21.13 & 0.000 & 1,26114 & 1,51905 \\
\hline cônjuge & .5051289 & .1069827 & 4.72 & 0.000 & .2954466 & .7148111 & .3937696 & .1048261 & 3.76 & 0.000 & .1883142 & .5992249 \\
\hline outracond & 1,35296 & .0822169 & 16.46 & 0.000 & 1,19182 & 1,5141 & 1,22236 & .0934892 & 13.07 & 0.000 & 1,03912 & 1,40559 \\
\hline aposent & 3,24023 & .0894899 & 36.21 & 0.000 & 3,06484 & 3,41563 & .5519627 & .1446667 & 3.82 & 0.000 & .2684212 & .8355043 \\
\hline Belém & .136648 & .0620934 & 2.20 & 0.028 & .0149472 & .2583489 & -.4341554 & .0812641 & -5.34 & 0.000 & -.5934302 & -.2748806 \\
\hline Fortaleza & .0636614 & .0570165 & 1.12 & 0.264 & -.048089 & .1754117 & -.1963279 & .0704193 & -2.79 & 0.005 & -.3343471 & -.0583087 \\
\hline Recife & .4007936 & .0559545 & 7.16 & 0.000 & .2911248 & .5104624 & .1524727 & .0654488 & 2.33 & 0.020 & .0241955 & .2807499 \\
\hline Salvador & -.1168159 & .0591752 & -1.97 & 0.048 & -.2327971 & -.0008347 & .0737354 & .0668972 & 1.10 & 0.270 & -.0573807 & .2048516 \\
\hline Belo Horizonte & -.2397425 & .0585707 & -4.09 & 0.000 & -.3545389 & -.124946 & -.3464083 & .0736274 & -4.70 & 0.000 & -.4907152 & -.2021013 \\
\hline Rio de Janeiro & .1510651 & .0537685 & 2.81 & 0.005 & .0456808 & .2564494 & -.2481978 & .0696215 & -3.56 & 0.000 & -.3846535 & -.1117421 \\
\hline Curitiba & -.596791 & .0725585 & -8.22 & 0.000 & -.739003 & -.4545791 & -.6566697 & .0952907 & -6.89 & 0.000 & -.843436 & -.4699034 \\
\hline Porto Alegre & -.3652677 & .0537107 & -6.80 & 0.000 & -.4705388 & -.2599967 & -.6572315 & .0729327 & -9.01 & 0.000 & -.800177 & -.514286 \\
\hline constante. & 4,72202 & .1502833 & 31.42 & 0.000 & 4,42747 & 5,01657 & $-2,0198$ & .1872519 & -10.79 & 0.000 & $-2,3868$ & $-1,652812$ \\
\hline
\end{tabular}

(empregado é a categoria base) 


\section{Efeitos marginais}

Se $y=\operatorname{Pr}$ (inativo) (predict, $\mathrm{p}$ outcome(inativo) $)=0,18221099$

Se $y=\operatorname{Pr}($ desempregado $)($ predict, $\mathrm{p}$ outcome $($ desempregado $))=0,08271039$

\begin{tabular}{|c|c|c|c|c|c|c|c|c|c|c|c|c|c|c|}
\hline Variable & $d y / d x$ & $\begin{array}{l}\text { Std. } \\
\text { Err. }\end{array}$ & $\mathbf{z}$ & $P>|z|$ & [95\% & :.I.] & X & $d y / d x$ & $\begin{array}{l}\text { Sta. } \\
\text { Err. }\end{array}$ & z & $|P>| z \mid$ & & & K \\
\hline \multicolumn{8}{|l|}{ inatividade } & \multicolumn{7}{|c|}{ desemprego } \\
\hline anoest & -.021934 & .00268 & -8.18 & 0.000 & .027192 & .016676 & 758.846 & .009588 & .00164 & 5.86 & 0.000 & .006383 & .012793 & 758.846 \\
\hline anoest $^{2}$ & -.0001957 & .00019 & -1.03 & 0.302 & -.000567 & .000176 & 74.925 & -.000614 & .0001 & -6.00 & 0.000 & -.000815 & -.000413 & 74.925 \\
\hline idade & -.0486844 & .00122 & -40.04 & 0.000 & -.051068 & -.046301 & 34.922 & .0026013 & .00061 & 4.25 & 0.000 & .001401 & .003801 & 34.922 \\
\hline rendaliq & .0000176 & .00000 & 5.79 & 0.000 & .000012 & .000024 & 1119.26 & $-8.36 e-06$ & .00000 & -5.11 & 0.000 & .000012 & $-5.2 \mathrm{e}-06$ & 1119.26 \\
\hline ncrianças & -.011095 & .00319 & -3.48 & 0.001 & -.017348 & .004842 & .555783 & .0012166 & .00195 & 0.62 & 0.532 & -.002599 & .005032 & .555783 \\
\hline nadultos & -.0044028 & .0018 & -2.45 & 0.014 & -.007927 & .000879 & 349.288 & .0029196 & .00107 & 2.74 & 0.006 & .000828 & .005011 & 349.288 \\
\hline pardo* & -.0080301 & .00576 & -1.39 & 0.163 & -.019312 & .003252 & .37146 & .0089176 & .00386 & 2.31 & 0.021 & .00136 & .016475 & .37146 \\
\hline negro* & -.0232953 & .00871 & -2.67 & 0.008 & -.040373 & -.006217 & .085092 & .0258268 & .00686 & 3.77 & 0.000 & .012389 & .039264 & .085092 \\
\hline cônjuge* & .0774525 & .02012 & 3.85 & 0.000 & .038025 & .11688 & .042081 & .0229827 & .0099 & 2.32 & 0.020 & .003572 & .042394 & .042081 \\
\hline outracond* & .2241417 & .01857 & 12.07 & 0.000 & .187738 & .260546 & .050021 & .0801826 & .01198 & 6.69 & 0.000 & .056699 & .103667 & .050021 \\
\hline aposent* & .6521676 & .014 & 46.57 & 0.000 & .624722 & .679614 & 118762 & -.0493851 & .00548 & -9.00 & 0.000 & -.060135 & -.038635 & .118762 \\
\hline Belém* & .027171 & .0099 & 2.74 & 0.006 & .007767 & .046575 & .036949 & -.0294216 & .00434 & -6.79 & 0.000 & .037919 & .020924 & .036949 \\
\hline Fortaleza* & .0125072 & .00861 & 1.45 & 0.147 & -.004378 & .029392 & .060107 & -.0147085 & .00451 & -3.26 & 0.001 & .023549 & .005868 & .060107 \\
\hline Recife* & .0634274 & .00958 & 6.62 & 0.000 & .04466 & .082195 & .065342 & .0047208 & .00496 & 0.95 & 0.341 & .005003 & .014445 & .065342 \\
\hline Salvador* & -.0179098 & .00807 & -2.22 & 0.026 & -.033722 & .002098 & .060021 & .0075453 & .00523 & 1.44 & 0.149 & -.002711 & .017801 & .060021 \\
\hline Belo Horizonte* & -.0294378 & .00774 & -3.80 & 0.000 & -.044608 & .014268 & .090418 & -.0207046 & .00451 & -4.59 & 0.000 & -.029542 & -.011867 & .090418 \\
\hline Rio de Janeiro* & .0268678 & .00829 & 3.24 & 0.001 & .010626 & .04311 & 205442 & -.0198064 & .00451 & -4.39 & 0.000 & -.028654 & .010959 & .205442 \\
\hline Curitiba* & -.0693269 & .00784 & -8.84 & 0.000 & -.084701 & .053953 & .060132 & -.0346986 & .0048 & -7.23 & 0.000 & -.044109 & .025288 & .060132 \\
\hline orto Alegre* & -.0427532 & .0068 & -6.29 & 0.000 & -.056074 & .029432 & .076285 & -.0366336 & .00382 & -9.58 & 0.000 & -.044125 & -.029142 & \\
\hline
\end{tabular}

$\left.{ }^{*}\right)$ dy/dx é para uma mudança discreta da varíavel dummy de 0 para 1. 